\title{
COMPARISON OF STATIONARY AND MOVING INFRARED THERMOMETER MEASUREMENTS ABOARD A CENTER PIVOT
}

\author{
P. D. Colaizzi, S. A. O’Shaughnessy, S. R. Evett, M. A. Andrade
}

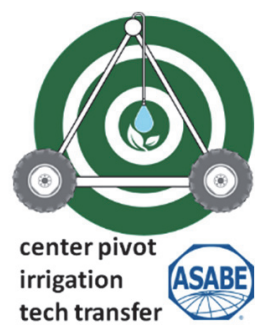

Collection

\author{
HighLIGHTS \\ - Stationary and moving infrared thermometers aboard a center pivot were compared. \\ - Comparisons were in terms of directional brightness temperature discrepancies. \\ - Discrepancies were within $1.8^{\circ} \mathrm{C}$, and many were within $1.0^{\circ} \mathrm{C}$. \\ - Larger discrepancies tended to occur for sparser vegetation cover.
}

ABSTRACT. Infrared thermometers (IRTS) can measure canopy temperature, which is useful for irrigation and crop management. Center pivot and lateral move irrigation systems are suitable platforms to transport IRTs across cropped fields at regular intervals. IRTs aboard center pivots, when used in conjunction with irrigation scheduling algorithms, have resulted in crop yield and crop water productivity that is equivalent to or greater than what can be achieved using soil water measurements of the root zone profile with a field-calibrated neutron probe. Irrigation scheduling algorithms perform best when stationary IRT measurements are supplemented with moving IRT arrays, where the former provides time series data and the latter provides spatially distributed data. However, the normal deflection of moving irrigation systems and other confounding factors have caused concern that moving IRT measurements may be degraded relative to stationary IRT measurements. Directional brightness temperatures $\left(T_{B}\right)$ measured by stationary and moving IRTs were compared over two corn and one potato season at the USDA Agricultural Research Service, Bushland, Texas. Moving and stationary $T_{B}$ were compared in terms of root mean square error, mean absolute error, and mean bias error, and were all $<1.8^{\circ} \mathrm{C}$, and many were $<1.0^{\circ} \mathrm{C}$, and $r^{2} \geq 0.95$. Error terms tended to be larger for potato, which had less vegetation cover compared with corn. However, error terms were similar to previous studies of calibration and spatial variability for IRTs and thermal imagers. Therefore, $T_{B}$ measurements of moving IRTs did not appear to be degraded relative to $T_{B}$ measurements of stationary IRTs for this study. However, interpretation of stationary and moving IRT measurements may be aided by addition of low cost imagers to distinguish vegetation from soil background.

Keywords. Canopy temperature, Crop management, Evapotranspiration, Irrigation, Remote sensing, Sensors.

(@) $(\Theta \Theta$ The authors have paid for open access for this article. This work is licensed under a Creative Commons AttributionNonCommercial-NoDerivatives 4.0 International License https://creative commons.org/licenses/by-nc-nd/4.0/

Submitted for review in April 2019 as manuscript number NRES 13443; approved for publication as part of the Center-Pivot Irrigation Tech Transfer Collection by the Natural Resources \& Environmental Systems Community of ASABE in September 2019.

Mention of company or trade names is for description only and does not imply endorsement by the USDA. The USDA is an equal opportunity provider and employer.

The authors are Paul D. Colaizzi, Research Agricultural Engineer, Susan A. O'Shaughnessy, Research Agricultural Engineer, Steven R. Evett, Research Soil Scientist, USDA Agricultural Research Service, Bushland, Texas; and Manuel A. Andrade, Oak Ridge Institute for Science and Education (ORISE) Fellow, Oak Ridge, Tennessee. Corresponding author: Paul D. Colaizzi, 300 Simmons RD, Unit 10 (USPS), 2300 Experiment Station Road (shipping), Bushland, TX 79012; phone: 806-3565763; e-mail: Paul.Colaizzi@ars.usda.gov.

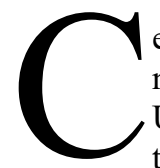

enter pivot and lateral move irrigation systems now account for over half the irrigated area in the United States (USDA-NASS, 2014), and continue to be adopted worldwide (FAO, 2019). Center pivot and lateral moves have been shown to be suitable platforms for transporting radiometers and imagers over cropped fields (Sadler et al., 2002; Peters and Evett, 2008; O'Shaughnessy et al., 2013; Osroosh et al., 2018). Radiometers and imagers used in this way provide spatially distributed multispectral and thermal data that are useful for managing crops in real time. Infrared thermometers (IRTs) mounted on center pivots, for example, can be used to measure crop canopy temperatures, which are useful to manage and automate irrigation schedules. Using arrays of IRTs aboard a center pivot, crop yield and crop water productivity were achieved that were similar to or better than irrigation scheduling using a field-calibrated neutron probe (O’Shaughnessy et al., 2015, 2017). Although aerial remote 
sensing platforms such as unmanned aerial vehicles (UAVs) have become technically feasible for real-time crop management (Santesteban et al., 2017; Quebrajo et al., 2018), they carry greater complexity and are more subject to weather and regulatory limitations compared with ground-based platforms (Sepúlveda-Reyes et al., 2016). There are also questions about the economic feasibility of using UAV platforms for thermal imaging, given the lengthy post processing required to provide reliably accurate thermometric images of a field. Therefore, efforts continue to develop and commercialize proximal remote sensing platforms and sensors aboard moving (center pivot and lateral move) irrigation systems (O'Shaughnessy et al., 2018; Osroosh et al., 2018).

An air- or ground-based moving platform used to transport remote sensors is usually subject to uncontrolled random movements (i.e., roll, pitch, and yaw), in addition to movement in the intended direction of travel. If random movements of the platform are transmitted to the on-board sensors, then measurements by the remote sensors may contain distortion and uncertainty in the intended target. For moving irrigation systems, practitioners have expressed concern that normal deflection of structural members during movement over a field may lead to excessive pitch, roll, and yaw of on-board sensors. For example, most thermal-based algorithms used in irrigation management require vegetation temperature, with minimal contamination from soil background temperature (Jackson, 1982; Huband and Monteith, 1986). IRTs used for this purpose must therefore be aimed at the crop canopy. This has long been known to be problematic during partial canopy cover, and soil background may impact the sensed data even after full canopy cover due to gaps in plant emergence (e.g., Osroosh et al., 2018, cf fig. $8 \mathrm{~b})$. Thus, structural deflection may inadvertently cause the IRTs to see more soil compared with vegetation. Since soil often has different daytime temperatures compared with transpiring vegetation, soil background may lead to misestimates of crop water stress. In the case of sunlit soil, which often is warmer than vegetation, this would be an overestimate of crop water stress (O'Shaughnessy et al., 2011). This could be addressed by using visible and/or thermal imagers to discriminate vegetation and soil in real time. However, IRTs presently offer several advantages over thermal imagers that are important for agricultural applications, such as simplicity, lower cost, lower power consumption, and perhaps most importantly, higher accuracy (e.g., Osroosh et al. 2018, cf table 4).

A concurrent issue with moving platforms is that data are typically obtained at only one time of day, but many variables derived from data are of interest over daily time spans (Jackson et al., 1983). Therefore, some method must be employed to scale instantaneous measurements over $24 \mathrm{~h}$ or longer. For IRTs, Peters and Evett (2004) showed that diurnal temperatures could be reconstructed from one-time-ofday measurements, which were referenced to diurnal (time series) measurements. This approach was used successfully in subsequent work where one-time-of-day measurements from moving IRTs were diurnally scaled using time series measurements from stationary (reference) IRTs (e.g., Peters and Evett, 2008; O'Shaughnessy et al., 2017; Colaizzi et al., 2017a). However, O'Shaughnessy et al. (2017) reported that mean seasonal integrated crop water stress index values for fully irrigated corn plots were almost $15 \%$ larger for moving compared with stationary IRTs, and attributed this to the moving IRTs viewing a larger proportion of soil and hence measuring larger surface temperatures. Their conjecture may have been confounded by differences in plot locations where stationary and moving IRT measurements were obtained, scaling one-time-of-day moving IRT measurements to the entire day (Peters and Evett, 2004), and the influence of atmospheric demand used in calculating the integrated crop water stress index on different days.

Temperatures reported by stationary and moving IRTs could have important differences that have not been explicitly investigated. The differences may be partially related to structural deflection of moving irrigation machines. There is a paucity of data on the impact of normal deflection on on-board sensors, but routine visual observation has provided anecdotal evidence. There are likely other confounding factors, which further justify comparison of data derived from stationary vs. moving platforms. Other studies using IRTs or thermal imagers have clearly documented the impact of sun-sensor angles (Wanjura and Upchurch, 1991), proximity to the ground (Kustas et al., 1990; Sepúlveda-Reyes et al., 2016), vegetation cover (Heilman et al., 1981), soil properties (Sadler et al., 2002), and other sources of spatial variability, including the sunlit and shaded components of vegetation and soil (Clawson and Blad, 1982; González-Dugo et al., 2006; Meron et al., 2013; Rud et al., 2014; Sepúlveda-Reyes et al., 2016; Han et al., 2016; Santesteban et al., 2017; Quebrajo et al., 2018). If consistently large or systematic differences exist between stationary and moving IRT temperatures, then further refinement of algorithms or moving sensors (e.g., declinometers or lowcost visible imagers) may be required. The objective of this study was to quantify temperature discrepancies of moving versus stationary IRTs, where IRTs measured the surface temperatures of irrigated crops, and the moving IRTs were aboard a center pivot.

\section{Materials ANd Methods REVIEW OF SURFACE TEMPERATURE COMPONENTS AND VIEW FACTORS}

This section reviews the relationships between the apparent temperature of a cropped surface reported by an IRT, its view factors, variables that determine view factors such as sensor deployment geometry, and some model assumptions. These relationships provide background as to why different temperatures should be expected for different IRT views (i.e., moving or stationary) of the same surface. The review is specific to IRTs, but can apply to other non-imaging radiometers.

Terminology follows that proposed by Norman and Becker (1995). The raw temperature reported by an IRT is termed the directional brightness temperature. Here, 'directional' refers to energy flux reaching a radiometer (i.e., the IRT) within a finite solid angle, whereas 'hemispherical' is energy flux in all directions. 'Hemispherical-directional' is energy impinging on a surface from all directions and reflected back within a solid finite angle. 'Brightness' refers to 
the temperature without considering emissivities of the surface, or non-emitted energy reaching the IRT (e.g., hemispherical-directional energy from the atmosphere); 'radiometric' temperature accounts for surface emissivities and other non-emitted energy.

Following Heilman et al. (1981) and Kustas et al. (1990), a general form of the energy balance between the directional brightness temperature of a surface having $n$ components, which is measured by an IRT, and the directional radiometric temperatures of each surface component and their view factors is:

$$
f_{I R T} \sigma_{*} T_{B}^{p}=\sum_{i=1}^{n} \epsilon_{i} \sigma_{*} v_{i} T_{i}^{p}+L W_{S K Y} \sum_{i=1}^{n}\left(1-\epsilon_{i}\right) v_{i}
$$

where $f_{\text {IRT }}$ is the IRT response function (unitless), $\sigma *$ is a wavelength-dependent constant $\left(\mathrm{W} \mathrm{m}^{-2} \mathrm{~K}^{-4}\right)$ that is analogous to (but not always the same as) the Stefan-Boltzmann constant, $T_{B}$ is the directional brightness temperature of the composite surface that is measured by an IRT $(\mathrm{K}), p$ is calculated by integrating the Planck law over the wavelengths of interest (unitless), $\varepsilon_{\mathrm{i}}, v_{i}$, and $T_{i}$ are the directional emissivity (unitless), view factor (unitless), and directional radiometric surface temperature $(\mathrm{K})$, respectively, of the ith surface component, $L W_{\mathrm{SKY}}$ is the downwelling hemispherical longwave irradiance from the sky $\left(\mathrm{W} \mathrm{m}^{-2}\right)$, where a small portion is reflected back into the IRT according to the hemispherical-directional reflectance term $\left(1-\varepsilon_{\mathrm{i}}\right)$.

Equation 1 can be applied to an IRT viewing a row crop with partial cover (fig. 1). Four main surface components ( $n$ $=4)$ included sunlit vegetation $(i=1)$, shaded vegetation $(i$

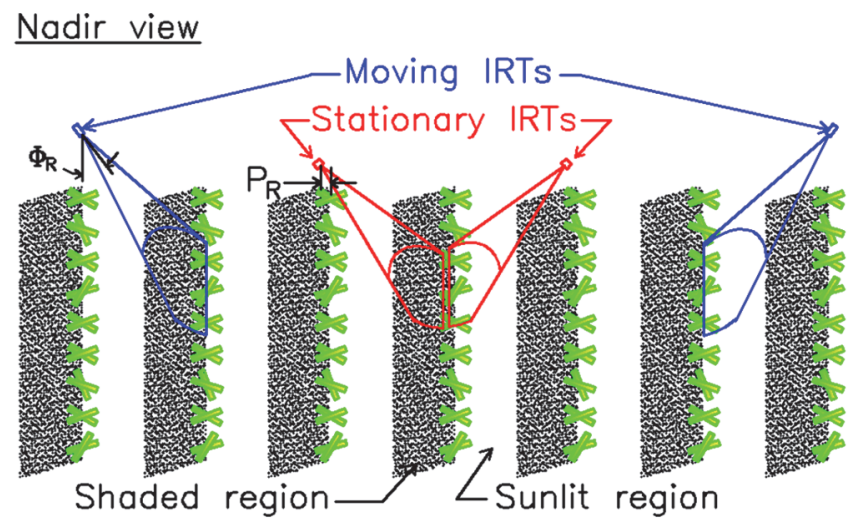

Lateral (down row) view

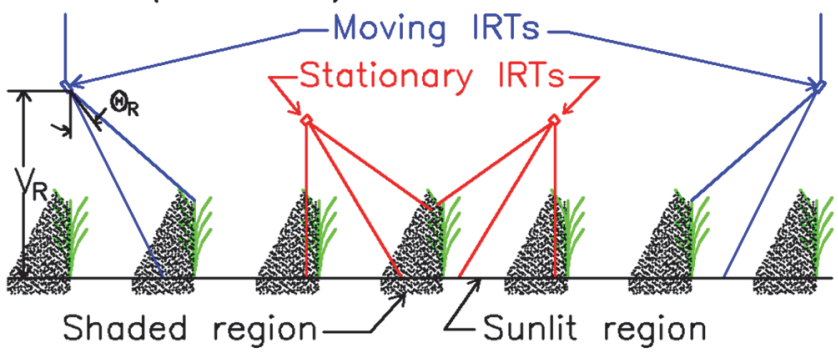

Figure 1. Detail of moving IRTs aboard an irrigation system passing over a row crop, stationary IRTs viewing a row crop, and possible IRT foot print locations and view factors. The view factors are the proportions of soil and vegetation and their sunlit or shaded components appearing within the IRT foot print, and change continuously with sun, sensor, and vegetation geometry. See text for symbols.
$=2)$, sunlit soil $(i=3)$, and shaded soil $(i=4)$. Constant values were assigned as $f_{I R T}=1.0, p=4.0$, and $\varepsilon_{\mathrm{i}}=\varepsilon=0.98$, based on the following:

1. The dependency of $T_{B}$ on the internal detector temperature is accounted for in $f_{I R T}$. The IRTs used in the present study (described later) were the same model as used in a previous study (Colaizzi et al., 2018), which showed that $f_{I R T}$ was sensor-specific, but assigning $f_{I R T}=1.0$ had virtually no impact on field and energy balance model tests in the previous study. This may have been related to relatively small differences $\left(<3.0^{\circ} \mathrm{C}\right)$ between detector and target temperatures and proprietary temperature compensating circuitry of the sensor. Therefore, we assumed $f_{I R T}$ $=1.0$.

2. The IRTs used in the present study were filtered from 5.5 to $14 \mu \mathrm{m}$, resulting in $p=5.13$ for $0 \leq T_{B} \leq 60^{\circ} \mathrm{C}$. However, integrating the Planck law over all wavelengths results in $p=4.0$, which had negligible impact compared with using other $p$ values.

3. For this application, directional emissivities can be assumed isotropic and independent of wavelength and view direction (Idso et al., 1976; Norman and Becker, 1995). The emissivity of most vegetation is $\sim 0.98$, but may increase to $\sim 0.99$ due to multiple reflections within a large canopy (Campbell and Norman, 1998). At the study location, dry, bare soil emissivity was estimated by a multiband thermal radiometer (model CE 312, Cimel Electronique, Paris, France), and also found as $\sim 0.98$. Therefore, we assumed that all $\varepsilon_{\mathrm{i}}=\varepsilon=0.98$.

From these assumptions and simplifying, equation (1) is rewritten as:

$$
\begin{gathered}
T_{B}^{4}= \\
\epsilon\left[v_{1} T_{1}^{4}+v_{2} T_{2}^{4}+v_{3} T_{3}^{4}+v_{4} T_{4}^{4}\right]+(1-\epsilon) \sigma_{S B}^{-1} L W_{S K Y}
\end{gathered}
$$

where $\sigma_{\mathrm{SB}}$ is the Stefan-Boltzmann constant $\left(5.67 \times 10^{-8} \mathrm{~W}\right.$ $\mathrm{m}^{-2} \mathrm{~K}^{-4}$ ) and was used in place of $\sigma^{*}$, and all other terms were as defined previously.

The view factor $\left(v_{\mathrm{i}}\right)$ is the area fraction of the ith component appearing in the IRT view and is defined as:

$$
v_{i}=\frac{A_{R i}}{A_{R}}
$$

where $A_{R i}$ is the area of the ith component that occupies the IRT view $\left(\mathrm{L}^{2}\right)$, and $A_{R}$ is the total area of the IRT view $\left(\mathrm{L}^{2}\right)$. Note that $0 \leq v_{\mathrm{i}} \leq 1.0$ and $\sum_{\mathrm{i}-1}{ }^{\mathrm{n}} v_{\mathrm{i}}=1.0$. Colaizzi et al. (2010) described and tested a geometrically-based model to calculate $A_{R i}$ and $A_{R}$. Briefly, a non-imaging radiometer (i.e., IRT) viewing a surface typically has a circular or elliptical footprint for nadir or off-nadir views, respectively, and

$$
A_{R}=f\left(\theta_{R}, V_{R}, F O V\right)
$$

where $\theta_{\mathrm{R}}$ is the radiometer zenith view angle relative to nadir, $V_{R}$ is the vertical height (L) from the surface to the radiometer, and FOV is the field-of-view of the radiometer, usually specified as $x: 1$, and is the ratio of the absolute distance from the radiometer to the surface (numerator) to the radiometer footprint diameter (minor axis if footprint is el- 
liptical) (denominator). A row crop can be represented geometrically as an elliptical hedgerow, and

$$
A_{R i}=f_{i}\left(A_{R}, h_{C}, w_{C}, L A I, \text { row }, \emptyset_{R}, P_{R}, \theta_{S}, \emptyset_{S}\right)
$$

where $h_{C}$ is the height of the crop canopy $(\mathrm{L}), w_{C}$ is the width of the crop canopy (L), $L A I$ is the leaf area index of the crop canopy $\left(\mathrm{L}^{2} \mathrm{~L}^{-2}\right)$, row is the crop row spacing $(\mathrm{L}), \varphi_{\mathrm{R}}$ is the radiometer azimuth view angle relative to the crop row direction (defined as $0^{\circ}$ for parallel and $90^{\circ}$ for perpendicular views), $P_{R}$ is the perpendicular offset (L) of the radiometer from the center of the crop row, $\theta_{\mathrm{S}}$ and $\varphi_{\mathrm{S}}$ are the solar zenith azimuth angles, respectively.

Inclusion of $\theta_{\mathrm{S}}$ and $\varphi_{\mathrm{S}}$ account for the sunlit and shaded components, and change continuously when direct beam solar irradiance is present. The $h_{C}, w_{C}$, and $L A I$ change with the growth and decline of the vegetation and can be specified at daily time intervals. The FOV and row are usually constant, and change only with the sensor or cropping practices, respectively.

The $\theta_{\mathrm{R}}, \varphi_{\mathrm{R}}, V_{R}$, and $P_{R}$ relate to the radiometer position (fig. 1). The $\theta_{\mathrm{R}}$ and $V_{R}$ are constant. The $\varphi_{\mathrm{R}}$ and $P_{R}$ are constant for a stationary radiometer. The $\varphi_{\mathrm{R}}$ and $P_{R}$ are also constant for a moving radiometer that does not traverse the crop rows (e.g., aboard a center pivot over circular crop rows, or aboard a lateral move over straight rows parallel to the direction of travel). Otherwise, $\varphi_{\mathrm{R}}$ and $P_{R}$ change continuously with the movement of a radiometer. It is important to note, however, that $\theta_{\mathrm{R}}, \varphi_{\mathrm{R}}, V_{R}$, and $P_{R}$ are the terms that vary with radiometer roll, pitch, and yaw (e.g., as related to the deflection of the radiometer mounting hardware). However, their relative importance on $v_{\mathrm{i}}$ is greater for intermediate canopy cover but less important for sparse or full canopy cover (Colaizzi et al., 2010). Also important is that for two or more radiometers viewing an identical surface region but having different $\theta_{\mathrm{R}}, \varphi_{\mathrm{R}}, V_{R}$, or $P_{R}$, each radiometer will have its unique set of $v_{i}$ (from eqs. 3, 4, and 5). Therefore, from equation 2, the same $T_{B}$ for different IRT views should not be expected (Wanjura and Upchurch, 1991; Norman and Becker, 1995). Even for full canopy cover, $T_{B}$ may vary by up to $\sim 1^{\circ} \mathrm{C}$ depending on the relative proportion of sunlit or shaded vegetation appearing in the IRT view (Wanjura and Upchurch, 1991). Further, view factor effects may be confounded by differences in IRT response functions (i.e., $f_{I R T} \neq$ 1.0 ) or differences in emissivities (i.e., $\varepsilon \neq \varepsilon_{\mathrm{i}} \neq 0.98$ ).

\section{Field MeAsurements}

The study was conducted at the USDA Agricultural Research Service Conservation and Production Research Laboratory, Bushland, Texas $\left(35^{\circ} 11^{\prime} \mathrm{N}, 102^{\circ} 6^{\prime} \mathrm{W}, 1170 \mathrm{~m}\right.$ above mean sea level). The soil is a Pullman clay loam (fine, mixed, superactive, thermic Torrertic Paleustoll), with three primary horizons, including an $\mathrm{Ap}$ ( 0 to $\sim 0.3 \mathrm{~m}), \mathrm{Bt}(\sim 0.3$ to $1.3 \mathrm{~m})$, and Btk $(>1.3 \mathrm{~m})$. The Bt horizon has a high clay content, and the Btk horizon has a high calcium carbonate content (USDA-NRCS, 2019). The Pullman soil has slow permeability and plant available water contents of approximately $140 \mathrm{~mm} \mathrm{~m}^{-1}$ (Evett et al., 2012; Tolk and Evett, 2012). The Pullman is one of the most extensive soils in the Northwest Texas region, covering over 1.5 million ha, and is well-suited for crop production, in part due to its small slopes $\left(\sim 0.0025 \mathrm{~m} \mathrm{~m}^{-1}\right)$ and low spatial variability (Unger and Pringle, 1981). The climate is semiarid with strong regional advection, a mean annual precipitation of $\sim 470 \mathrm{~mm}$, and Class A Pan evaporation of $\sim 2600 \mathrm{~mm}$.

Data were obtained over three crop seasons, including corn in 2016, corn in 2017, and potato in 2018 (table 1). The crops were planted in circular rows on raised beds, spaced $0.76 \mathrm{~m}$, and were irrigated by a three-span center pivot irrigation system with a variable rate irrigation (VRI) zone control add-on package (model 8000, Valmont Irrigation, Inc., Valley, Neb.). The center pivot had a $191 \mathrm{~m}$ total radius, with drops spaced $1.52 \mathrm{~m}$, and was irrigated in alternate interrows using low energy precision application (LEPA) drag socks (Bordovsky, 2019). Crops were planted in half of the center pivot field where the experimental plots were part of larger replicated studies on irrigation scheduling and crop water productivity (e.g., O’Shaughnessy et al., 2015) (fig. 2). Irrigations were scheduled using a field-calibrated neutron probe. Full irrigation was defined as replacing soil water in the $1.5-\mathrm{m}$ soil profile when $25 \mathrm{~mm}$ of soil water depletion was measured by the neutron probe (Evett et al., 2012), and irrigation rates were designated as a percentage of full irrigation for each irrigation event (i.e., $30 \%, 50 \%, 60 \%, 80 \%$, $100 \%$ in table 1). Crops were planted in the spring, and furrow dikes were installed in each interrow following crop establishment to reduce surface movement of irrigation and precipitation water (Howell et al., 2002). The furrow dikes were required to achieve high distribution uniformity of LEPA on the slowly permeable Pullman soil (Schneider and Howell, 2000). Agronomic and irrigation practices were similar to those practiced on commercial farms in the Southern High Plains region for high crop yield and high crop water productivity.

Directional brightness temperatures were measured by stationary and moving IRTs with wireless data transmission (model SapIP-IRT, Dynamax, Inc., Houston, Tex.) during

Table 1. Crop seasons where brightness temperature measurements were compared using stationary and moving infrared thermometers.

\begin{tabular}{|c|c|c|c|c|c|c|c|c|c|c|}
\hline \multicolumn{2}{|l|}{ Year } & \multicolumn{3}{|c|}{2016} & \multicolumn{3}{|c|}{2017} & \multicolumn{3}{|c|}{2018} \\
\hline Crop & & \multicolumn{3}{|c|}{ Corn } & \multicolumn{3}{|c|}{ Corn } & \multicolumn{3}{|c|}{ Potato } \\
\hline Variety & & \multicolumn{3}{|c|}{ P1151AM } & \multicolumn{3}{|c|}{ P1151AM } & \multicolumn{3}{|c|}{ FL-1867 } \\
\hline Plant date & & \multicolumn{3}{|c|}{$5 / 13 / 2016$} & \multicolumn{3}{|c|}{$5 / 14 / 2017$} & \multicolumn{3}{|c|}{$4 / 6-4 / 10 / 2018$} \\
\hline Plant DOY & & \multicolumn{3}{|c|}{134} & \multicolumn{3}{|c|}{134} & \multicolumn{3}{|c|}{$96-100$} \\
\hline Seed population & $\mathrm{m}^{-2}$ & \multicolumn{3}{|c|}{8.2} & \multicolumn{3}{|c|}{8.5} & \multicolumn{3}{|c|}{8.6} \\
\hline In season precipitation & $\mathrm{mm}$ & \multicolumn{3}{|c|}{285} & \multicolumn{3}{|c|}{482} & \multicolumn{3}{|c|}{260} \\
\hline Harvest dates & & \multicolumn{3}{|c|}{$10 / 3-10 / 12 / 2016$} & \multicolumn{3}{|c|}{$10 / 11 / 2017$} & \multicolumn{3}{|c|}{$8 / 13 /-8 / 22 / 2018$} \\
\hline Harvest DOYs & & \multicolumn{3}{|c|}{$277-286$} & \multicolumn{3}{|c|}{284} & \multicolumn{3}{|c|}{$220-225$} \\
\hline Plot number & & 42 & 30 & 23 & 30 & 23 & 42 & 34 & 27 & 38 \\
\hline Irrigation rate & & $30 \%$ & $50 \%$ & $80 \%$ & $30 \%$ & $50 \%$ & $80 \%$ & $60 \%$ & $80 \%$ & $100 \%$ \\
\hline In season irrigation & $\mathrm{mm}$ & 156 & 254 & 400 & 147 & 191 & 241 & 368 & 445 & 547 \\
\hline
\end{tabular}




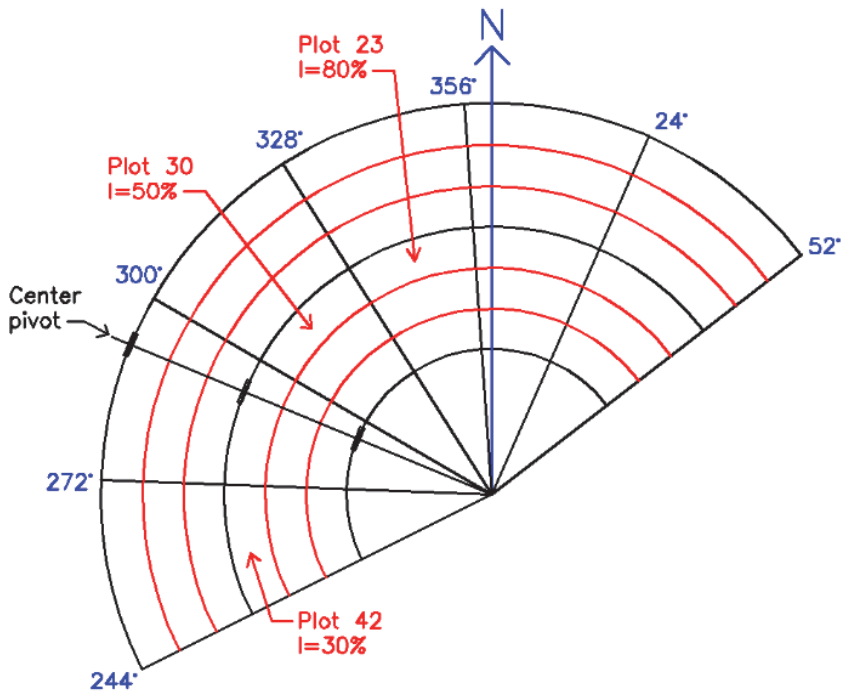

(a)

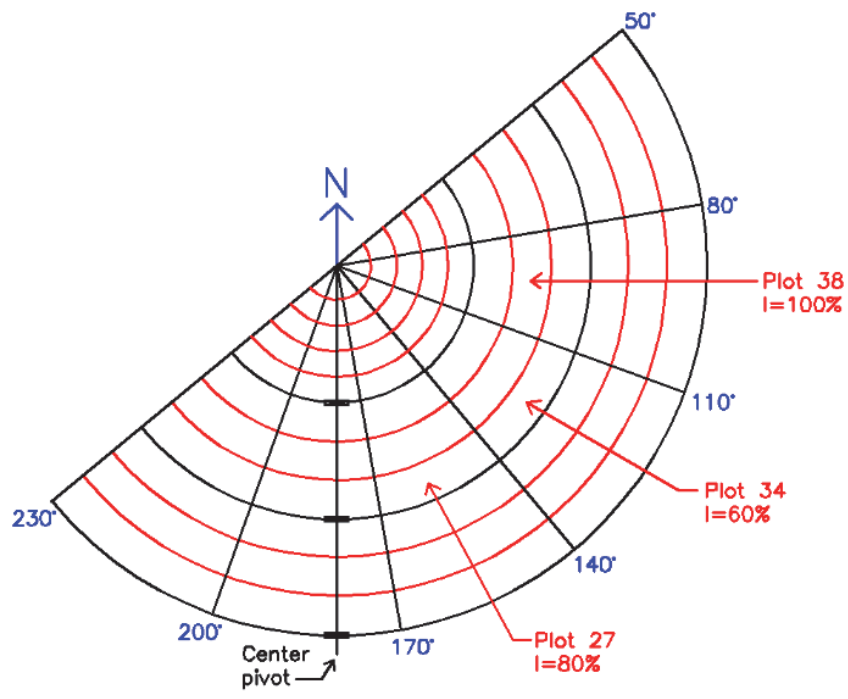

(c)

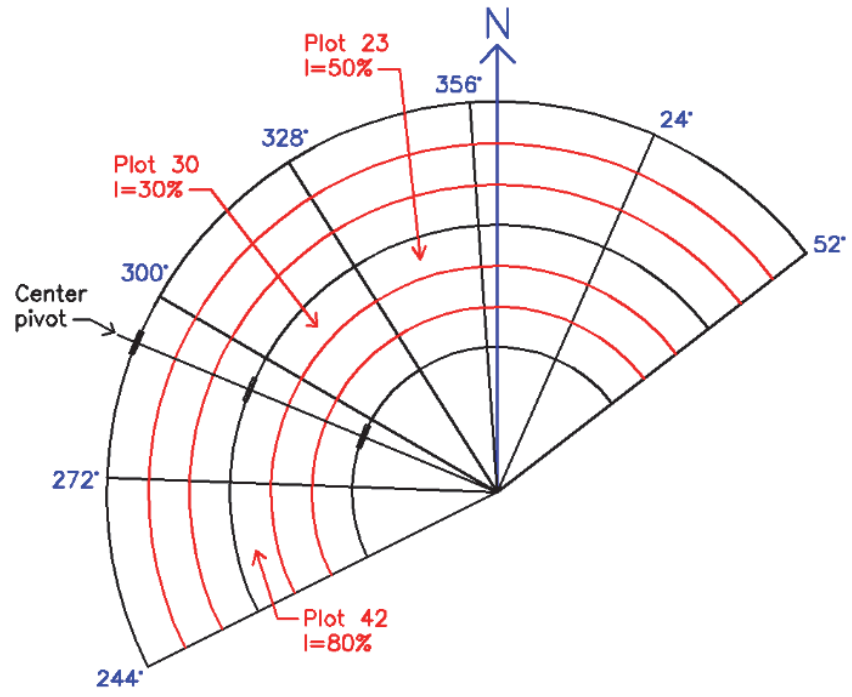

(b)

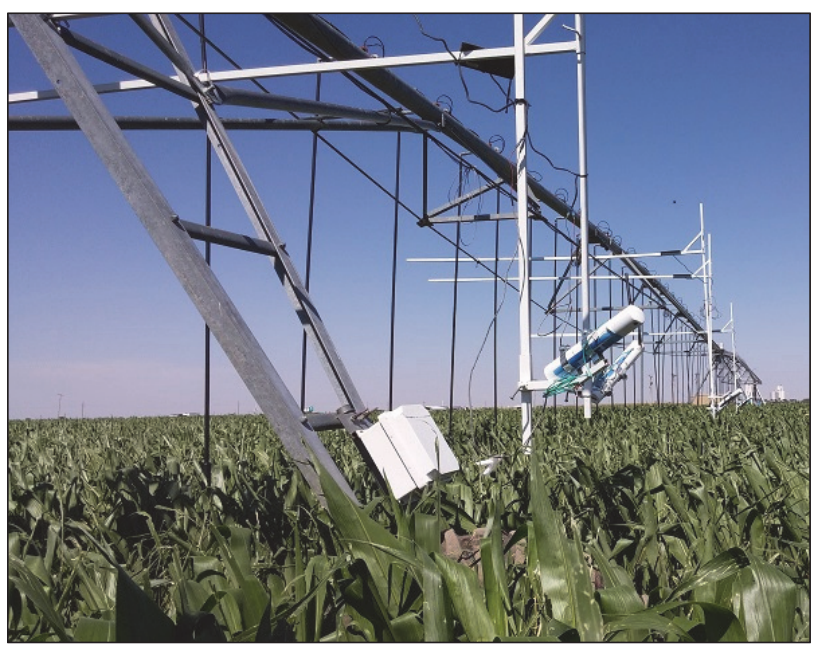

(d)

Figure 2. Locations of plots containing stationary IRTs and locations of moving IRTs along the center pivot that pass over the stationary IRTs during (a) 2016 corn; (b) 2017 corn (damaged by hail on 2 July), (c) 2018 potato; and (d) moving IRT and mounting bracket aboard center pivot (2017 corn, Plot 42). $I$ = irrigation rate.

each crop season. The IRTs were based on a design developed by O'Shaughnessy et al. (2011). The IRTs used the Zigbee wireless protocol (IEEE 802.15.1, 2005), had a 3:1 field-of-view, and were filtered from 5.5 to $14 \mu \mathrm{m}$. The infrared sensor included proprietary signal conditioning circuitry to compensate for detector temperature (model MLX90614-BCF, Melexis, Ypres, Belgium).

Stationary IRT measurements used in the present study were obtained in three experimental plots having different irrigation rates (table 1; fig. 2). Stationary IRTs were deployed on vertical masts near the center of each plot; plots were 18 rows wide, and rows were oriented parallel to the center pivot direction of travel. Each plot location included three IRTs, where two IRTs viewed the crop canopy and one IRT viewed the soil. The two IRTs viewing the canopy were deployed in adjacent rows and termed "inner" and "outer," which were relative to the center pivot point. Moving IRTs were deployed on masts mounted to the center pivot (fig. 2d). Two moving IRTs were mounted on each mast, and viewed the field surface in opposite directions, including the plots where the stationary IRTs were deployed as the center pivot passed over. The moving IRT pairs that viewed a given plot were also termed "inner" and "outer," depending on their relative distance from the center pivot point. The moving IRTs were numbered from the inner to outer location along the pivot; the stationary IRTs were numbered according to the factory serial number. Viewing the canopy in opposite directions was intended to integrate the effects of a sunlit and shaded canopy (Wanjura and Upchurch, 1991; O'Shaughnessy et al., 2013). Simultaneous stationary and moving IRT measurements were available only in the three experimental plots during each crop season. Despite this limitation, the study was deemed justified by the low spatial variability of the Pullman soil, extensive time series data for each crop season, and three crop seasons having different canopy structures. 
The IRTs were aimed at the center of a crop row at night using a machined laser jig containing a cross laser (model Infiniter Red Line Cross Module, Quarton, Inc., Chino, Calif.). The deployment geometry parameters $\left(\theta_{\mathrm{R}}, \varphi_{\mathrm{R}}, V_{R}\right.$, and $P_{R}$ ) were measured and recorded (table 2). The $h_{C}$ and $w_{C}$ were measured approximately biweekly in each experimental plot and interpolated between measurement days by cumulative growing degree days after planting. LAI was estimated using an allometric method based on plant population and height, and growing degree days after planting (Colaizzi et al., 2017b). The IRT deployment geometry and crop canopy sizes were used to calculate IRT view factors $\left(v_{i}\right)$ described earlier. The vegetation view factor $\left(v_{V E G}\right)$ was calculated as the sum of sunlit $\left(v_{1}\right)$ and shaded $\left(v_{2}\right)$ vegetation components (i.e., $v_{V E G}=v_{1}+v_{2}$, eqs. 3 to 5) at daily time steps. The complement of $v_{V E G}$ is the substrate (i.e., soil) view factor (i.e., $v_{S O I L}=1-v_{V E G}$ ). Some variation in deployment geometry parameters, mainly for stationary IRTs, was the result of (1) ensuring as much vegetation was viewed as possible, especially early in the season when considerable gaps were still present between individual plants; (2) placing the IRT footprint as close to soil water measurement areas as

\begin{tabular}{|c|c|c|c|c|c|c|c|}
\hline Season & Plot, Tmt. & IRT\# & Position & $\begin{array}{c}\theta_{\mathrm{R}}^{[\mathrm{b}]} \\
\left(^{\circ}\right)\end{array}$ & $\begin{array}{c}\varphi_{\mathrm{R}}{ }^{[\mathrm{c}]} \\
\left(^{\circ}\right)\end{array}$ & $\begin{array}{l}\mathrm{V}_{\mathrm{R}}{ }^{[\mathrm{d}]} \\
(\mathrm{m})\end{array}$ & $\begin{array}{l}P_{R}^{[e]} \\
(\mathrm{m})\end{array}$ \\
\hline \multirow[t]{11}{*}{ Corn 2016} & 42 & 78 & Outer & 55 & 49 & 2.34 & 0.23 \\
\hline & $30 \%$ & 79 & Inner & 32 & 45 & 2.24 & 0.15 \\
\hline & & 80 & Soil & 24 & 0 & 0.43 & 0.28 \\
\hline & 30 & 81 & Outer & 56 & 44 & 2.26 & 0.23 \\
\hline & $50 \%$ & 82 & Inner & 45 & 38 & 2.26 & 0.20 \\
\hline & & 83 & Soil & 20 & 0 & 0.42 & 0.36 \\
\hline & 23 & 84 & Outer & 60 & 43 & 2.41 & 0.15 \\
\hline & $80 \%$ & 85 & Inner & 40 & 38 & 2.34 & 0.20 \\
\hline & & 86 & Soil & 25 & 0 & 0.41 & 0.20 \\
\hline & Moving IRT & 5 & Inner & 45 & 45 & 2.5 & 0 \\
\hline & Moving IRT & 6 & Outer & 45 & 30 & 2.5 & 0 \\
\hline \multirow[t]{11}{*}{ Corn 2017} & 30 & 81 & Outer & 45 & 27 & 2.92 & 0.48 \\
\hline & $30 \%$ & 82 & Inner & 45 & 22 & 2.79 & 0.46 \\
\hline & & 72 & Soil & 15 & 0 & 0.32 & 0.38 \\
\hline & 23 & 84 & Outer & 49 & 34 & 2.85 & 0.46 \\
\hline & $50 \%$ & 65 & Inner & 50 & 20 & 2.85 & 0.46 \\
\hline & & 86 & Soil & 12 & 0 & 0.34 & 0.41 \\
\hline & 42 & 78 & Outer & 34 & 34 & 2.69 & 0.28 \\
\hline & $80 \%$ & 79 & Inner & 34 & 32 & 2.82 & 0.58 \\
\hline & & 67 & Soil & 23 & 0 & 0.33 & 0.41 \\
\hline & Moving IRT & 5 & Inner & 45 & 45 & 2.5 & 0 \\
\hline & Moving IRT & 6 & Outer & 45 & 30 & 2.5 & 0 \\
\hline \multirow[t]{13}{*}{ Potato 2018} & 34 & 81 & Outer & 47 & 24 & 1.83 & 0 \\
\hline & $60 \%$ & 221 & Inner & 30 & 0 & 1.88 & 0 \\
\hline & & 72 & Soil & 5 & 0 & 0.41 & 0.38 \\
\hline & 27 & 78 & Outer & 27 & 24 & 1.73 & 0 \\
\hline & $80 \%$ & 79 & Inner & 37 & 0 & 1.75 & 0 \\
\hline & & 74 & Soil & 12 & 0 & 0.43 & 0.38 \\
\hline & 38 & 84 & Outer & 47 & 24 & 1.88 & 0 \\
\hline & $100 \%$ & 65 & Inner & 33 & 0 & 1.83 & 0 \\
\hline & & 86 & Soil & 0 & 0 & 0.33 & 0.38 \\
\hline & Moving IRT & 9 & Inner & 45 & 45 & 2.5 & 0 \\
\hline & Moving IRT & 10 & Outer & 45 & 30 & 2.5 & 0 \\
\hline & Moving IRT & 11 & Inner & 45 & 45 & 2.5 & 0 \\
\hline & Moving IRT & 12 & Outer & 45 & 30 & 2.5 & 0 \\
\hline \multicolumn{8}{|c|}{ [a] See figure 1 and text for definition of symbols. } \\
\hline \multicolumn{8}{|c|}{ [b] $\theta_{\mathrm{R}}=$ Zenith view angle relative to vertical. } \\
\hline \multicolumn{8}{|c|}{ [c] $\varphi_{R}=$ Azimuth view angle, where $0^{\circ}$ is parallel and $90^{\circ}$ is perpendicular to crop row direction. } \\
\hline \multicolumn{8}{|c|}{ [d] $V_{R}=$ Vertical sensor height relative to soil surface. } \\
\hline \multicolumn{8}{|c|}{ [e] $P_{R}=$ Horizontal sensor position relative to center of crop row. } \\
\hline
\end{tabular}

practical; (3) avoid locating IRT masts in interrows designated for foot traffic; and (4) avoid locating IRT masts in interrows where irrigation drop pipes passed.

The IRTs obtained measurements approximately every $1 \mathrm{~min}$ and transmitted data wirelessly via routers to an embedded computer located at the pivot point. Data were stored and transmitted periodically to remote desktop computers by a fiber optic link. Prior to field deployment, IRT calibration and function were checked using a procedure described in Colaizzi et al. (2018). The angular location of the center pivot was recorded, and moving IRT measurements used in the analysis were limited to those recorded within a $\pm 2.5^{\circ}$ angle of the stationary IRT locations in each experimental plot. The $\pm 2.5^{\circ}$ angle was imposed to ensure the moving IRTs were within the treatment plots containing the stationary IRTs, and no more than $\sim 6 \mathrm{~m}$ from the stationary IRT locations as the moving IRTs passed overhead. Moving IRT measurements included days with or without irrigation events. Measured $T_{B}$ discrepancies related to IRTs viewing both wet and dry surfaces were assumed minimized because irrigation was by LEPA drag sock, and moving IRTs viewed the surface well ahead of each LEPA drop. Data were screened by visual inspection of diurnal graphs of IRT $T_{B}$

Table 2. Infrared thermometer location and deployment geometry used to calculate vegetation view factors. 
and ambient air temperature measurements in each experimental plot for each day of all three crop seasons. The graphs included the three stationary IRTs (stationary IRT-inner, stationary IRT-outer, and stationary IRT-soil) and two moving IRTs (moving IRTx-inner and moving IRTy-outer, where $\mathrm{x}$ and $y$ designate the $x$ th or $y$ th IRT along the center pivot). Moving IRT measurements spanning $2 \mathrm{~h}$ after sunrise and $2 \mathrm{~h}$ before sunset were only used; other times were discarded due to lack of surface temperature spatial variability (Peters and Evett, 2004), which would artificially reduce IRT discrepancies. Days containing gaps in the stationary IRT data were discarded; data gaps sometimes occurred due to IRT or router malfunctions, or maintenance issues requiring the embedded computer to be reset. Measurements of center pivot structural deflection and IRT declination were not obtained because these were not germane to the original research objectives of irrigation scheduling and crop water productivity, but the study included stationary and moving IRT measurements at the same field locations and at the same times that were not previously available.

The $T_{B}$ measured by the IRTs were compared in three ways, including comparing the two stationary IRTs, the two moving IRTs, and the average of the stationary and moving IRT pairs. Discrepancies in each comparison were quantified by calculating the root mean square error (RMSE), mean absolute error (MAE), mean bias error (MBE), and the intercept (a), slope (b), and coefficient of determination $\left(r^{2}\right)$ of a simple linear regression. Quantifying discrepancies in this way was deemed more instructive over simply reporting standard pair-wise comparison tests because other studies reported similar discrepancy measures, such as IRT calibration (O'Shaughnessy et al., 2011; Colaizzi et al., 2018; Osroosh et al., 2018) or spatial variability (Kustas et al., 1990; French et al., 2007; Han et al., 2016). The discrepancies were calculated using $T_{B}$ measured at the original 1-min frequency and time-averaged over $10 \mathrm{~min}$.

\section{RESULTS}

Early season growing conditions were favorable during all three seasons at the study location. This resulted in rapid vegetative growth, and relatively large $v_{V E G}$ (and small $v_{S O I L}$ ) occurred before all stationary and moving IRTs could be deployed and operational (figs. 3, 4, and 5). Hence most IRT measurements were obtained over nearly complete canopy cover, when $v_{V E G}$ were both largest and had little variation between IRTs, where variation in $v_{V E G}$ were related to different view geometries (table 2). This would be desired in practical applications to minimize uncertainty in the vegetation temperature component, and this was sought by aiming IRTs at the center of the crop row. Conversely, a wider range of $v_{V E G}$ would have been desired for the present study, and also to test algorithms for extracting vegetation temperature from $T_{B}$, where $T_{B}$ may include both vegetation and soil in the IRT field of view (Jackson, 1982; Peters and Evett, 2008; O'Shaughnessy et al., 2018).

Calculated $v_{V E G}$ were mostly between 0.9 and 1.0 for the 2016 corn (fig. 3) and 2017 corn (fig. 4) seasons when moving IRTs passed over the plots containing the stationary
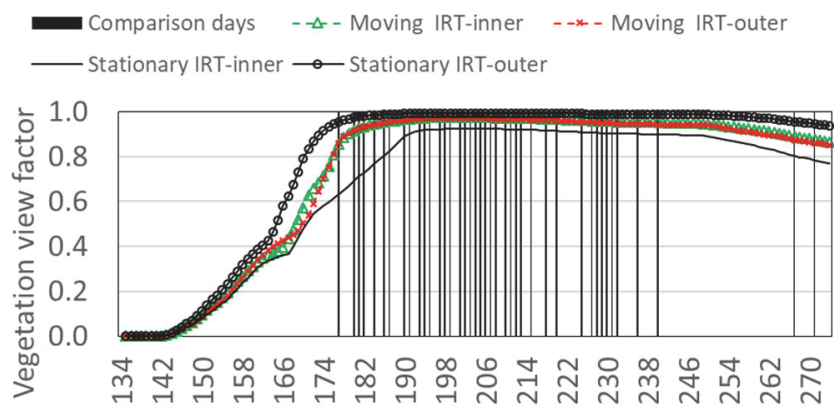

Day of Year

(a)

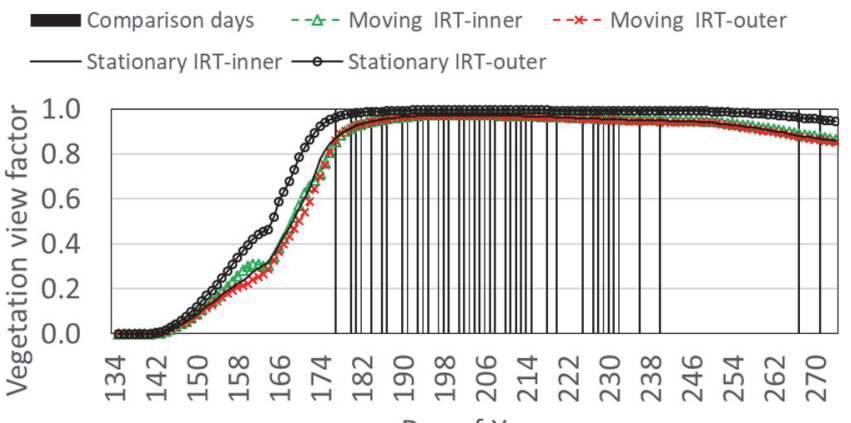

Day of Year

(b)
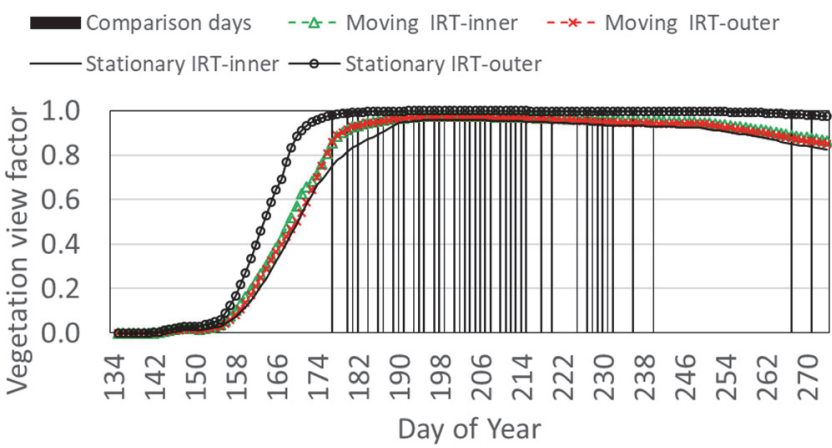

(c)

Figure 3. Vegetation view factor ( $\left.V_{V E G}\right)$ in IRT field-of-view (calculated by eqs. 3 to 5), and days when moving and stationary IRT measurements were compared (vertical bars) during the 2016 corn season; (a) Plot 42, 30\% irrigation rate; (b) Plot 30, 50\% irrigation rate; (c) Plot $23,80 \%$ irrigation rate.

IRTs. There were a few days early and late in the seasons when $v_{V E G}$ were below 0.9, such as for the 2016 corn, Plot 42 (30\% irrigation rate), stationary IRT-inner (fig. 3a), but most were 0.8 or larger. On 2 July 2017 (DOY 183), the corn canopy was severely damaged by hail at approximately 7 to 8 leaf stage, and the measured $w_{C}$ was narrower because many leaves were bent downward near the stalk or torn off. However, this did not appear to reduce the calculated $v_{V E G}$ (fig. 4) because plants were sufficiently tall (1.1 to $1.2 \mathrm{~m})$ and $\theta_{R}$ and $\varphi_{R}$ were sufficient to avoid viewing most soil background (table 2). This result was somewhat unexpected because $L A I$ would likely have been reduced compared with undamaged corn ( $L A I$ field measurements were not obtained), but sufficient $L A I$ apparently remained so that $v_{V E G}$ was not reduced for the $\theta_{R}$ and $\varphi_{R}$ used. For the two corn seasons, there were fewer measurement days available in 2017 (fig. 4) compared with 2016 (fig. 3) because there was 

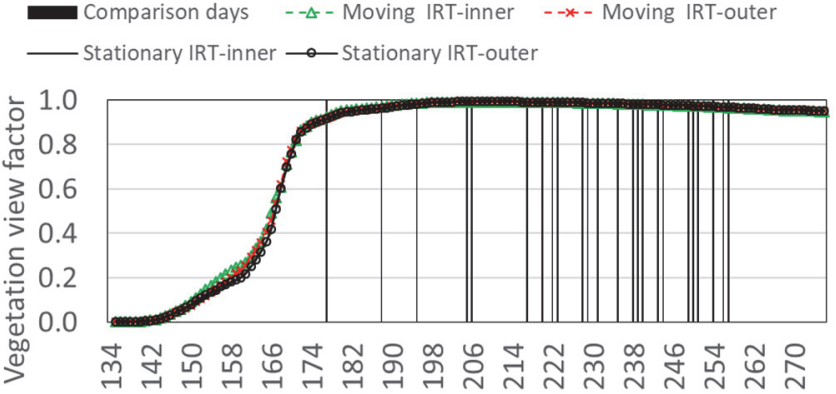

Day of Year

(a)
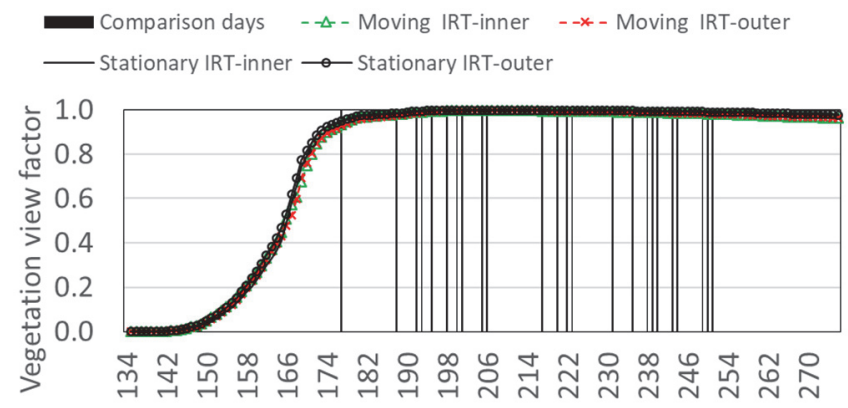

Day of Year

(b)

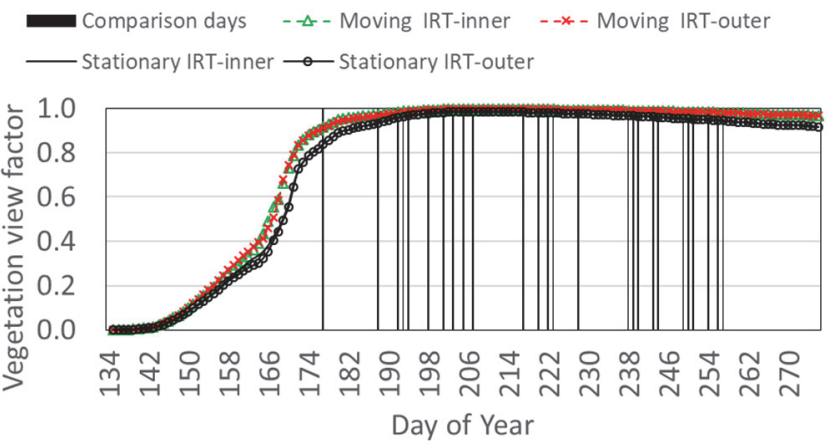

(c)

Figure 4. Vegetation view factor (VVEG) in IRT field-of-view (calculated by eqs. 3 to 5), and days when moving and stationary IRT measurements were compared (vertical bars) during the 2017 corn season; (a) Plot 30, 30\% irrigation rate; (b) Plot 23, 50\% irrigation rate; (c) Plot $42,80 \%$ irrigation rate.

greater precipitation and less irrigation was required (table 1). Therefore, the center pivot and on-board moving IRTs passed over the field less times in 2017 compared with 2016. During moving-stationary IRT comparison days in 2018 , the potato $w_{C}$ was $\sim 0.51$ to $0.55 \mathrm{~m}$ (i.e., fraction of cover was $\sim 66$ to $72 \%$ for 0.76 -m row spacing), and the potato $h_{C}$ was $\sim 0.62$ to $0.74 \mathrm{~m}$ (data not shown). Despite having a much smaller canopy compared with corn, the potato calculated $v_{V E G}$ were between 0.7 and 0.9 for Plot $34(60 \%$ irrigation rate) (fig. 5a) and Plot 27 (80\% irrigation rate) (fig. $5 \mathrm{~b}$ ), and most potato $v_{V E G}$ were greater than 0.9 for Plot 38 (100\% irrigation rate) (fig. $5 \mathrm{c}$ ).

The $T_{B}$ measurement discrepancies between stationary and moving IRTs were quantified for 2016 corn (table 3), 2017 corn (table 4), and 2018 potato (table 5 ). Here, $T_{B}$ is reported in units of ${ }^{\circ} \mathrm{C}$ instead of $\mathrm{K}$ for consistency with previous studies. The 2016 corn had larger $T_{B}$ discrepancies for the moving

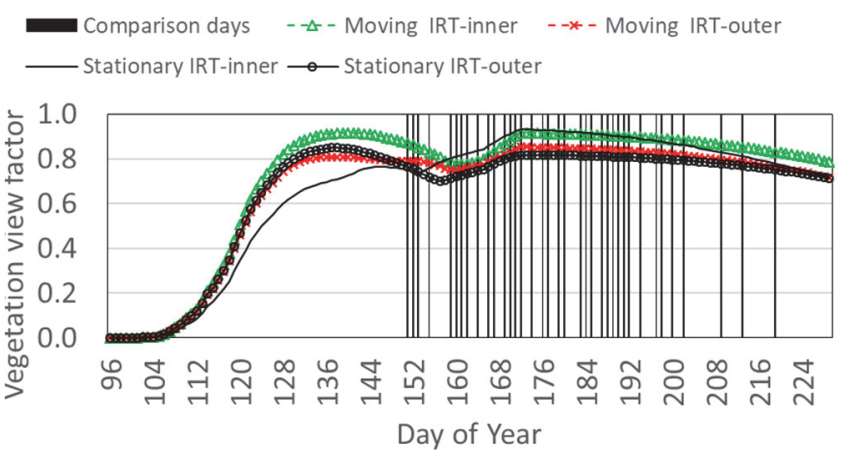

(a)

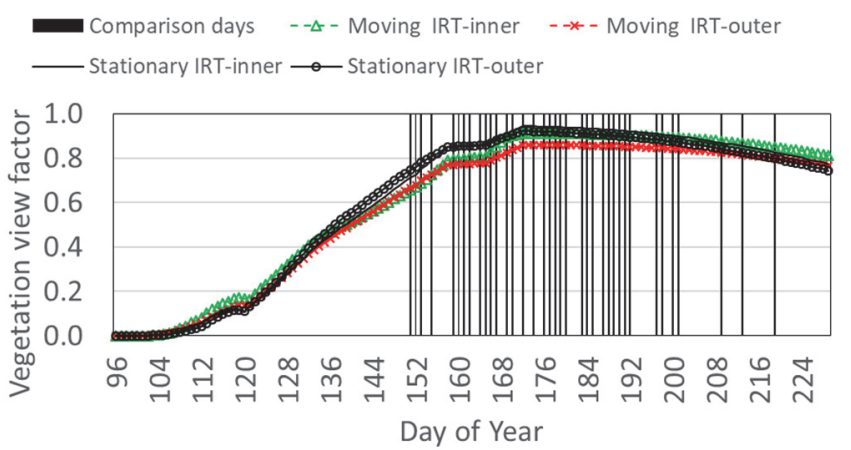

(b)
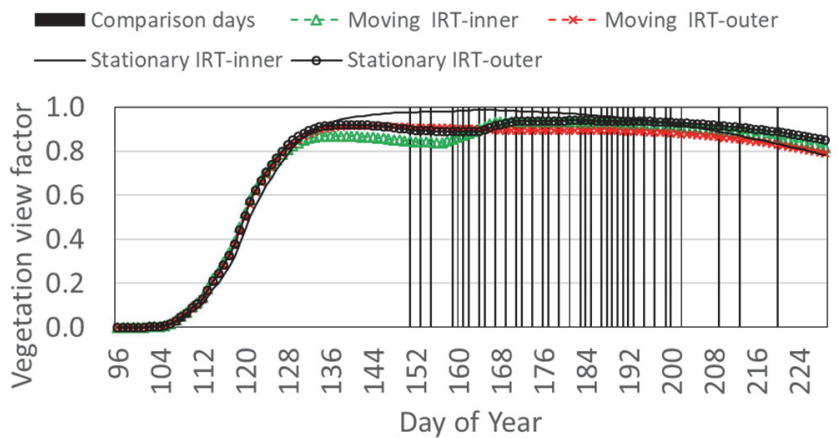

(c)

Figure 5. Vegetation view factor ( VVEG) in IRT field-of-view (calculated by eqs. 3 to 5), and days when moving and stationary IRT measurements were compared (vertical bars) during the 2018 potato season; (a) Plot 34, 60\% irrigation rate; (b) Plot 27, 80\% irrigation rate; (c) Plot $38,100 \%$ irrigation rate.

inner versus outer IRTs compared with the stationary inner versus outer IRTs, or the average of the moving versus average of the stationary IRTs for the three experimental plots (table 3). Error terms (RMSE, MAE, MBE) were all within $1.8^{\circ} \mathrm{C}$, intercepts and slopes were mostly significantly different than zero or one, respectively $(\alpha<0.05)$, and $\mathrm{r}^{2} \geq 0.95 . T_{B}$ were from $\sim 10^{\circ} \mathrm{C}$ to $\sim 40^{\circ} \mathrm{C}$ (fig. 6a), as were ambient air temperatures (data not shown) for both stationary and moving IRTs. $T_{B}$ discrepancies were mostly unaffected whether measurements with or without time averaging were used, or by irrigation rates $(30 \%, 50 \%$, or $80 \%)$. Time averaging (10 min) did not greatly reduce error terms compared with 1-min measurements, with differences $<0.5^{\circ} \mathrm{C}$, and most differences were within $0.1^{\circ} \mathrm{C}$. Many $T_{B}$ error terms (tables 3, 4, and 5) were somewhat larger compared with a previous calibration study using the same IRT model, where uncalibrated IRTs were 
Table 3. Brightness temperature measurement discrepancies between stationary and moving infrared thermometers. ${ }^{[a]}$

\begin{tabular}{|c|c|c|c|c|c|c|c|c|}
\hline $\begin{array}{c}\text { Plot, } \\
\text { Irrig. Tmt. }\end{array}$ & Comparison & $\mathrm{n}$ & $\begin{array}{c}\text { RMSE } \\
\left({ }^{\circ} \mathrm{C}\right)\end{array}$ & $\begin{array}{c}\text { MAE } \\
\left({ }^{\circ} \mathrm{C}\right)\end{array}$ & $\begin{array}{c}\mathrm{MBE} \\
\left({ }^{\circ} \mathrm{C}\right)\end{array}$ & $\begin{array}{c}\text { Intercept } \\
\left({ }^{\circ} \mathrm{C}\right)\end{array}$ & Slope & $\mathrm{r}^{2}$ \\
\hline \multicolumn{9}{|c|}{ Without time averaging (1-min data) } \\
\hline 42 & Stationary inner vs. outer & 516 & 0.73 & 0.52 & 0.31 & 0.04 & 1.01 & 0.99 \\
\hline \multirow[t]{2}{*}{$30 \%$} & Moving inner vs. outer & 516 & 1.76 & 1.09 & 1.02 & -2.47 & 1.13 & 0.96 \\
\hline & Avg. moving vs. avg. stationary & 516 & 0.85 & 0.60 & -0.41 & 1.28 & 0.94 & 0.99 \\
\hline 30 & Stationary inner vs. outer & 499 & 0.65 & 0.45 & 0.14 & -0.08 & 1.01 & 0.99 \\
\hline \multirow[t]{2}{*}{$50 \%$} & Moving inner vs. outer & 499 & 1.45 & 0.95 & 0.81 & 0.13 & 1.03 & 0.97 \\
\hline & Avg. moving vs. avg. stationary & 499 & 0.85 & 0.68 & -0.22 & 0.14 & 0.99 & 0.98 \\
\hline 23 & Stationary inner vs. outer & 500 & 1.02 & 0.69 & 0.44 & -1.48 & 1.08 & 0.98 \\
\hline \multirow[t]{2}{*}{$80 \%$} & Moving inner vs. outer & 500 & 1.35 & 0.98 & 0.71 & 0.85 & 0.99 & 0.96 \\
\hline & Avg. moving vs. avg. stationary & 500 & 1.29 & 0.93 & -0.50 & 1.97 & 0.90 & 0.97 \\
\hline \multicolumn{9}{|c|}{ Time averaging (10-min average) } \\
\hline 42 & Stationary inner vs. outer & 72 & 0.77 & 0.53 & 0.29 & 0.21 & 1.00 & 0.99 \\
\hline \multirow[t]{2}{*}{$30 \%$} & Moving inner vs. outer & 72 & 1.76 & 1.10 & 1.07 & -2.29 & 1.12 & 0.96 \\
\hline & Avg. moving vs. avg. stationary & 72 & 0.83 & 0.58 & -0.42 & 1.14 & 0.95 & 0.99 \\
\hline 30 & Stationary inner vs. outer & 71 & 0.67 & 0.47 & 0.13 & -0.10 & 1.01 & 0.99 \\
\hline \multirow[t]{2}{*}{$50 \%$} & Moving inner vs. outer & 71 & 1.50 & 0.94 & 0.87 & 0.10 & 1.03 & 0.97 \\
\hline & Avg. moving vs. avg. stationary & 71 & 0.86 & 0.70 & -0.14 & -0.09 & 1.00 & 0.98 \\
\hline 23 & Stationary inner vs. outer & 72 & 1.01 & 0.70 & 0.43 & -1.43 & 1.07 & 0.98 \\
\hline \multirow[t]{2}{*}{$80 \%$} & Moving inner vs. outer & 72 & 1.41 & 0.99 & 0.69 & 1.59 & 0.96 & 0.95 \\
\hline & Avg. moving vs. avg. stationary & 72 & 1.23 & 0.89 & -0.45 & 1.58 & 0.92 & 0.96 \\
\hline
\end{tabular}

[a] Measurements were without time averaging and with time averaging (up to 10 time series measurements).

Corn 2016 season; see figure 6 a for scatter plots.

compared to a black body radiator for target and ambient temperatures from $15^{\circ} \mathrm{C}$ to $55^{\circ} \mathrm{C}$, and error terms were $0.25^{\circ} \mathrm{C}$ to $1.5^{\circ} \mathrm{C}$ (Colaizzi et al., 2018).

The 2017 corn season had mostly similar $T_{B}$ discrepancies compared with the 2016 corn season, except the moving inner versus outer IRT discrepancies were smaller (table 4). All error terms (RMSE, MAE, and MBE) were within $1.1^{\circ} \mathrm{C}$, and most were within $0.8^{\circ} \mathrm{C} . T_{B}$ were $\sim 15$ to $\sim 40^{\circ} \mathrm{C}$, and had less scatter compared with the 2016 season (fig. 6b). Similar to 2016, time averaging and irrigation rates had little bearing on overall $T_{B}$ discrepancies. At first, the mostly smaller discrepancies in 2017 (compared with 2016) were not expected because qualitative visual assessments indicated large spatial variability of canopy damage following the hail event. However, $h_{C}$ and $w_{C}$ measurements resulted in calculated
$v_{V E G}$ greater than 0.9 for most moving-stationary IRT comparison days, meaning that $T_{B}$ consisted mostly of canopy temperature (from eqs. 2 to 5). This implied that spatial variability of canopy damage did not necessarily result in commensurate spatial variability of canopy temperatures.

The 2018 potato season had mostly larger $T_{B}$ discrepancies compared with both corn seasons (table 5 , fig. $6 \mathrm{c}$ ). $T_{B}$ ranged from $\sim 10^{\circ} \mathrm{C}$ to $40^{\circ} \mathrm{C}$ for the $80 \%$ and $100 \%$ irrigation rates, but up to $\sim 50{ }^{\circ} \mathrm{C}$ for the $60 \%$ irrigation rate because of larger $v_{\text {SOIL }}$ (fig. 5). This was in contrast to the 2017 corn season, with larger $v_{V E G}$ (fig. 4) and less moving versus stationary $T_{B}$ scatter (fig. 6b). Bare, dry, sunlit soil may exceed non-water stressed canopy temperatures by $\sim 25^{\circ} \mathrm{C}$ or more (e.g., Kustas et al., 1990; Han et al., 2016; Osroosh et al., 2018), implying that the composite $T_{B}$ may be relatively sensitive to small, local spatial variability of $v_{V E G}$ and $v_{S O I L}$, if

Table 4. Brightness temperature measurement discrepancies between stationary and moving infrared thermometers. ${ }^{[a]}$

\begin{tabular}{|c|c|c|c|c|c|c|c|c|}
\hline $\begin{array}{c}\text { Plot, } \\
\text { Irrig. Tmt. }\end{array}$ & Comparison & $\mathrm{n}$ & $\begin{array}{c}\text { RMSE } \\
\left({ }^{\circ} \mathrm{C}\right)\end{array}$ & $\begin{array}{c}\mathrm{MAE} \\
\left({ }^{\circ} \mathrm{C}\right)\end{array}$ & $\begin{array}{c}\mathrm{MBE} \\
\left({ }^{\circ} \mathrm{C}\right)\end{array}$ & $\begin{array}{c}\text { Intercept } \\
\left({ }^{\circ} \mathrm{C}\right)\end{array}$ & Slope & $\mathrm{r}^{2}$ \\
\hline \multicolumn{9}{|c|}{ Without time averaging (1-min data) } \\
\hline 30 & Stationary inner vs. outer & 468 & 0.77 & 0.52 & 0.14 & 0.98 & 0.97 & 0.98 \\
\hline \multirow[t]{2}{*}{$30 \%$} & Moving inner vs. outer & 335 & 0.79 & 0.54 & -0.17 & -0.43 & 1.01 & 0.98 \\
\hline & Avg. moving vs. avg. stationary & 468 & 0.72 & 0.52 & -0.28 & 0.81 & 0.96 & 0.98 \\
\hline 23 & Stationary inner vs. outer & 589 & 0.61 & 0.35 & 0.27 & 0.22 & 1.00 & 0.99 \\
\hline \multirow[t]{2}{*}{$50 \%$} & Moving inner vs. outer & 291 & 0.65 & 0.49 & 0.06 & -0.45 & 1.02 & 0.99 \\
\hline & Avg. moving vs. avg. stationary & 589 & 0.89 & 0.63 & 0.45 & 0.55 & 1.00 & 0.98 \\
\hline 42 & Stationary inner vs. outer & 547 & 0.60 & 0.46 & 0.07 & 1.99 & 0.92 & 0.99 \\
\hline \multirow[t]{2}{*}{$80 \%$} & Moving inner vs. outer & 359 & 1.10 & 0.89 & -0.49 & -1.79 & 1.05 & 0.95 \\
\hline & Avg. moving vs. avg. stationary & 547 & 0.86 & 0.66 & 0.49 & 1.57 & 0.96 & 0.98 \\
\hline \multicolumn{9}{|c|}{ Time averaging (10-min average) } \\
\hline 30 & Stationary inner vs. outer & 55 & 0.74 & 0.49 & 0.12 & 0.95 & 0.97 & 0.98 \\
\hline \multirow[t]{2}{*}{$30 \%$} & Moving inner vs. outer & 41 & 0.77 & 0.54 & -0.20 & -0.37 & 1.01 & 0.98 \\
\hline & Avg. moving vs. avg. stationary & 55 & 0.65 & 0.47 & -0.27 & 0.82 & 0.96 & 0.99 \\
\hline 23 & Stationary inner vs. outer & 66 & 0.58 & 0.35 & 0.28 & 0.17 & 1.00 & 0.99 \\
\hline \multirow[t]{2}{*}{$50 \%$} & Moving inner vs. outer & 33 & 0.55 & 0.44 & 0.06 & -0.46 & 1.02 & 0.99 \\
\hline & Avg. moving vs. avg. stationary & 66 & 0.86 & 0.63 & 0.44 & 0.67 & 0.99 & 0.99 \\
\hline 42 & Stationary inner vs. outer & 62 & 0.58 & 0.46 & 0.05 & 2.03 & 0.92 & 0.99 \\
\hline \multirow[t]{2}{*}{$80 \%$} & Moving inner vs. outer & 40 & 1.10 & 0.89 & -0.53 & -1.58 & 1.04 & 0.95 \\
\hline & Avg. moving vs. avg. stationary & 62 & 0.85 & 0.66 & 0.52 & 1.50 & 0.96 & 0.98 \\
\hline
\end{tabular}

[a] Measurements were without time averaging and with time averaging (up to 10 time series measurements).

Corn 2017 season; see figure 6b for scatter plots. 
Table 5. Brightness temperature measurement discrepancies between stationary and moving infrared thermometers.

\begin{tabular}{|c|c|c|c|c|c|c|c|c|}
\hline $\begin{array}{l}\text { Plot, } \\
\text { Irrig. Tmt. }\end{array}$ & Comparison & $\mathrm{n}$ & $\begin{array}{c}\text { RMSE } \\
\left({ }^{\circ} \mathrm{C}\right)\end{array}$ & $\begin{array}{l}\text { MAE } \\
\left({ }^{\circ} \mathrm{C}\right)\end{array}$ & $\begin{array}{l}\mathrm{MBE} \\
\left({ }^{\circ} \mathrm{C}\right)\end{array}$ & $\begin{array}{c}\text { Intercept } \\
\left({ }^{\circ} \mathrm{C}\right)\end{array}$ & Slope & $\mathrm{r}^{2}$ \\
\hline \multicolumn{9}{|c|}{ Without time averaging (1-min data) } \\
\hline 34 & Stationary inner vs. outer & 272 & 0.95 & 0.68 & -0.67 & 1.40 & 0.92 & 0.99 \\
\hline \multirow[t]{2}{*}{$60 \%$} & Moving inner vs. outer & 296 & 0.84 & 0.58 & 0.24 & 1.98 & 0.92 & 0.96 \\
\hline & Avg. moving vs. avg. stationary & 400 & 1.58 & 1.32 & -1.03 & -1.50 & 1.02 & 0.96 \\
\hline 27 & Stationary inner vs. outer & 436 & 1.35 & 1.01 & 0.43 & 3.64 & 0.88 & 0.91 \\
\hline \multirow{2}{*}{$80 \%$} & Moving inner vs. outer & 264 & 1.34 & 0.88 & -0.22 & 4.80 & 0.80 & 0.92 \\
\hline & Avg. moving vs. avg. stationary & 436 & 1.68 & 1.25 & -0.63 & -0.87 & 1.01 & 0.87 \\
\hline 38 & Stationary inner vs. outer & 417 & 1.39 & 0.88 & -0.48 & 3.55 & 0.83 & 0.98 \\
\hline \multirow[t]{2}{*}{$100 \%$} & Moving inner vs. outer & 363 & 0.89 & 0.55 & 0.25 & 0.67 & 0.98 & 0.97 \\
\hline & Avg. moving vs. avg. stationary & 417 & 1.38 & 0.96 & -0.46 & -1.90 & 1.06 & 0.96 \\
\hline \multicolumn{9}{|c|}{ Time averaging (10-min average) } \\
\hline 34 & Stationary inner vs. outer & 37 & 1.16 & 0.84 & -0.84 & 1.42 & 0.92 & 0.99 \\
\hline \multirow[t]{2}{*}{$60 \%$} & Moving inner vs. outer & 37 & 0.68 & 0.55 & 0.16 & 0.90 & 0.97 & 0.98 \\
\hline & Avg. moving vs. avg. stationary & 55 & 1.50 & 1.22 & -0.93 & -2.10 & 1.04 & 0.97 \\
\hline 27 & Stationary inner vs. outer & 57 & 1.41 & 1.03 & 0.50 & 2.79 & 0.91 & 0.90 \\
\hline \multirow[t]{2}{*}{$80 \%$} & Moving inner vs. outer & 34 & 1.53 & 1.03 & -0.13 & 5.13 & 0.80 & 0.90 \\
\hline & Avg. moving vs. avg. stationary & 57 & 1.58 & 1.16 & -0.19 & -2.77 & 1.09 & 0.89 \\
\hline 38 & Stationary inner vs. outer & 56 & 1.68 & 1.13 & -0.85 & 4.26 & 0.79 & 0.98 \\
\hline \multirow[t]{2}{*}{$100 \%$} & Moving inner vs. outer & 48 & 0.86 & 0.55 & 0.27 & 0.63 & 0.98 & 0.98 \\
\hline & Avg. moving vs. avg. stationary & 56 & 1.42 & 0.87 & -0.22 & -2.20 & 1.08 & 0.95 \\
\hline
\end{tabular}

[a] Measurements were without time averaging and with time averaging (up to 10 time series measurements).

Potato 2018 season; see figure $6 \mathrm{c}$ for scatter plots.

$v_{\text {SOIL }}$ is greater than $\sim 0.1$ (eq. 2). Calculated $v_{V E G}$ for moving and stationary IRTs differed more for the 2018 potato season (fig. 5) compared with the corn seasons (figs. 3 and 4). Therefore, corresponding differences in moving versus stationary $T_{B}$ scatter would also be expected, as shown by inspection of figure 6 . In addition to differences in $v_{V E G}$ and $v_{\text {SOIL }}$, discrepancies in $T_{B}$ may have been confounded by nonisotropic canopy and soil temperatures (such as a drying soil), or non-isotropic sunlit and shaded component view factors (such as under partly cloudy skies).

Several outliers were apparent in scatter plots of moving versus stationary IRT brightness temperatures, including the 2016 corn, Plot 23 (80\% irrigation rate) (fig. 6a). Here, the average moving IRT $T_{B}$ exceeded the average stationary IRT $T_{B}$ by up to $8^{\circ} \mathrm{C}$, visible as the outlying points above the $1: 1$ line (fig. 6a). These occurred on DOY 180, when calculated $v_{V E G}$ differed by up to 0.2 (fig. $3 \mathrm{c}$ ). On DOY 180 , the moving IRT-outer $T_{B}$ was similar to the soil $T_{B}$ at daily time fraction $\sim 0.6$ ( 14:24 CST) (fig. 7a). The soil $T_{B}$ had several peaks, which were well above the other non-soil $T_{B}$, and likely occurred when the soil was temporarily illuminated by direct sunlight. However, the moving IRT-inner $T_{B}$ was between the stationary IRT-outer and stationary IRT-inner $T_{B}$ at the same time. This implied that the stationary IRT-inner, stationary IRT-outer, and moving IRT-inner were viewing mostly vegetation, whereas the moving IRT-outer was viewing all or nearly all soil. This could be related to roll, pitch, and yaw of the IRT due to structural deflection of the center pivot, or spatial variability of vegetation, or both. Also, there were several instances in 2016 where moving IRT $T_{B}$ were less than stationary IRT $T_{B}$; these were visible as several points below the 1:1 line (fig. 6a). These occurred on DOY 206, also around time fraction $\sim 0.6$ (14:24 CST) during an irrigation event (fig. 7b). This implied that the moving IRTs viewed the wet surface before the stationary IRTs, seen as the sharp drop in $T_{B}$ after the moving IRT time window for Plot 23 had elapsed. This could be caused by movement of irrigation water along the interrow surface due to erosion of furrow dikes, since numerous irrigation events had occurred by DOY 206.

Similarly, for the 2018 potato season, several outlying points were visible above the 1:1 line (fig. 6c), but a hypothesis to explain this was not as straightforward as the 2016 corn example on DOY 180 (fig. 7a). In 2018, DOY 155, Plot 34 (60\% irrigation rate), the soil $T_{B}$ had a clear peak to $\sim 40^{\circ} \mathrm{C}$, above all other non-soil $T_{B}$ during time fractions from $\sim 0.50$ to $\sim 0.65$ (12:00 to $15: 30 \mathrm{CST}$ ) (fig. $7 \mathrm{c}$ ). However, moving IRT $T_{B}$ were between the stationary IRT inner and outer $T_{B}$, and were less than the soil $T_{B}$, implying these IRTs were viewing mostly vegetation. Also, on DOY 155 , Plot 38 (100\% irrigation rate), the moving IRT-inner $T_{B}$ was $\sim 35^{\circ} \mathrm{C}$ to $38^{\circ} \mathrm{C}$, clearly larger than the all other stationary IRT $T_{B}$ (fig. $7 \mathrm{~d}$ ), and similar to the soil $T_{B}$ in Plot 34 at this time (fig. $7 \mathrm{c}$ ). Here, the moving IRT-outer $T_{B}$ data were missing due to a malfunction. Also, at that time, the soil $T_{B}$ in Plot 38 was less than all other $T_{B}$, probably because it was shaded and/or wet by irrigation, in contrast to the soil $T_{B}$ in Plot 34. However, the moving IRT-inner in Plot 38 (fig. 7d) may have been viewing a local area of dry, sunlit soil (recall irrigation was applied in alternate interrows).

\section{DISCUSSION}

The $T_{B}$ discrepancies in the present study were generally not greater than previous studies that used different platforms. The $T_{B}$ discrepancies for stationary IRT pairs, moving IRT pairs, and moving versus stationary averages were all within $1.8^{\circ} \mathrm{C}$, and many were within $1.0^{\circ} \mathrm{C}$, and $\mathrm{r}^{2} \geq 0.95$ for the three crop seasons (tables 3, 4, and 5). Interannual discrepancies were inconsistent; for instance, discrepancies were smallest for stationary and largest for moving IRT pairs for 2016 corn (consistent with the results of O'Shaughnessy et al., 2017), but not for the other seasons. However, the magnitude of discrepancies were similar to results of previous studies involving IRTs or thermal imagers over cropped surfaces. Kustas et al. (1990) compared $T_{B}$ measured by an 

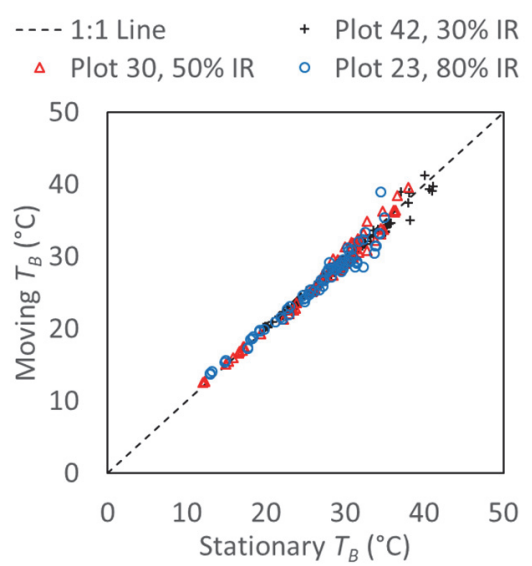

(a)
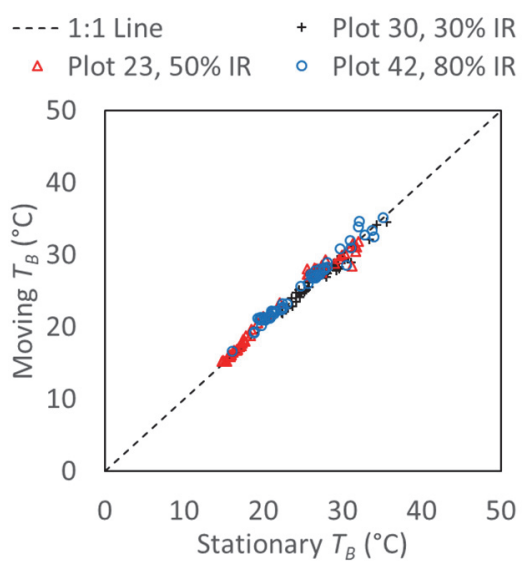

(b)
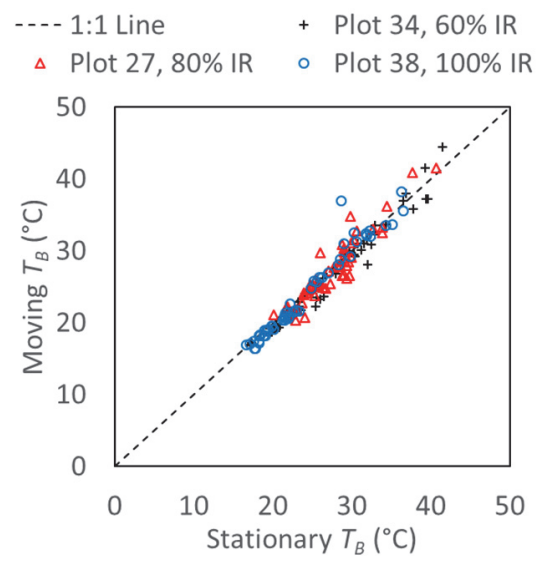

(c)

Figure 6. Moving vs. stationary TB, 10-min time average, for (a) 2016 corn season; (b) 2017 corn season; and (c) 2018 potato season. $I R=I r-$ rigation rate. See tables 3,4 , and 5 for statistics.

airborne IRT with $T_{B}$ calculated using ground based IRT measurements of component temperatures (essentially eq. 2 herein) for cotton with $\sim 20 \%$ cover, and found RMSE < $1.5^{\circ} \mathrm{C}$. Using an airborne thermal imager over a cotton season, González-Dugo et al. (2006) showed that extracted canopy temperature pixels had standard deviations between $\sim 0.5^{\circ} \mathrm{C}$ and $\sim 1.5^{\circ} \mathrm{C}$ for crop water stress indices from 0 to $\sim 0.6$. Han et al. (2016) showed that sunlit and shaded leaf temperatures of corn had standard deviations from $\sim 1^{\circ} \mathrm{C}$ to $\sim 5^{\circ} \mathrm{C}$ for different deficit irrigation treatments, but modeled versus measured canopy temperatures had $\mathrm{r}^{2}=0.98$. At least some of the discrepancies could be related to sensor response variation that was found in a calibration study of the same IRT model, where RMSE, MAE, and MBE between IRTs and a black body radiator were $0.25^{\circ} \mathrm{C}$ to $1.5^{\circ} \mathrm{C}$ (Colaizzi et al., 2018). French et al. (2007) considered $\sim 1.5^{\circ} \mathrm{C}$ to be the upper limit of accuracy required for $T_{B}$ measurements used in evapotranspiration model applications. The RMSE and MAE were consistent with O'Shaughnessy et al. (2011), where a prototype IRT of a similar design was evaluated, and Osroosh et al. (2018), who developed a low-cost thermal imager. However, most variation in sensor response in the cited studies resulted when differences were large $\left(>\sim 20^{\circ} \mathrm{C}\right)$ between ambient temperature (assumed in equilibrium with internal detector temperature) and target temperature. These differences were much larger compared with those typically seen in field conditions $\left(<\sim 10^{\circ} \mathrm{C}\right)$, even at the semiarid study location. Therefore, other factors unrelated to sensor response also likely contributed to discrepancies; we postulate that these were mainly related to view factors.

Overall $T_{B}$ discrepancies tended to be larger for the potato season, which had somewhat smaller $v_{V E G}$ and larger $v_{S O I L}$ compared with both corn seasons. During most of the season, $v_{V E G}$ among moving and stationary IRTs viewing the potato crop varied by $\sim 0.1$ or less (fig. 5). However, large differences in vegetation and soil temperatures $\left(>\sim 10^{\circ} \mathrm{C}\right)$, which are more likely at partial vegetation cover, would result in $T_{B}$ being sensitive to view factors (eq. 2; Kustas et al., 1990; Colaizzi et al., 2010), leading to the larger scatter in figure $6 \mathrm{c}$ (potato) compared with figures $6 \mathrm{a}$ and $6 \mathrm{~b}$ (corn). This implied that if more IRT measurements were obtained earlier in each season when canopy cover was smaller, then larger $T_{B}$ discrepancies could have resulted. We also speculate that more hilly terrain or greater soil spatial variability could have induced greater structural deflection of the center pivot, leading to more random movement of the IRT, greater uncertainly in $v_{V E G}$, and further exacerbating $T_{B}$ discrepancies. Based on the results of the present and previous studies, and given the importance of $v_{V E G}$ in interpreting $T_{B}$, we recommend addition of a low-cost imager capable of providing real-time estimates of view factors used in equation 2, used in conjunction with IRTs, regardless of the moving sensor platform used (O'Shaughnessy et al., 2018).

\section{CONCLUSION}

The $T_{B}$ discrepancies between stationary and moving IRTs reported herein were not considered large or systematic compared with previous studies. The RMSE, MAE, and MBE were $<1.8^{\circ} \mathrm{C}$, and many were $<1.0^{\circ} \mathrm{C}$, and $\mathrm{r}^{2} \geq 0.95$ for the three crop seasons. These discrepancies were generally no larger than those seen in other studies using platforms that did not involve sensors aboard moving irrigation systems. However, the present study was limited to nearly full canopy cover (vegetation view factors $>0.7$ ), and relatively flat terrain. Larger $T_{B}$ discrepancies could conceivably have resulted for more midrange vegetation view factors (say, 0.20 to 0.70 ), and/or if structural deflection of the moving irrigation system was larger, such as for more hilly terrain. 


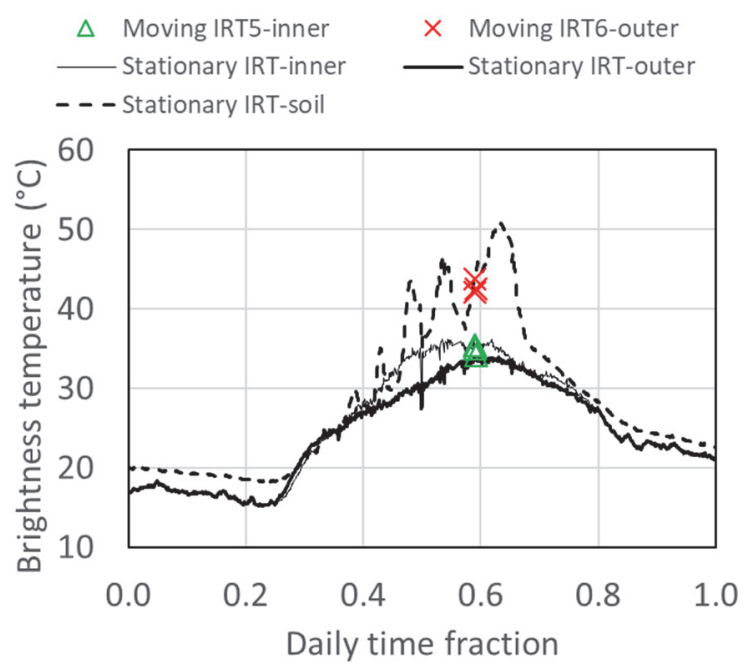

(a)

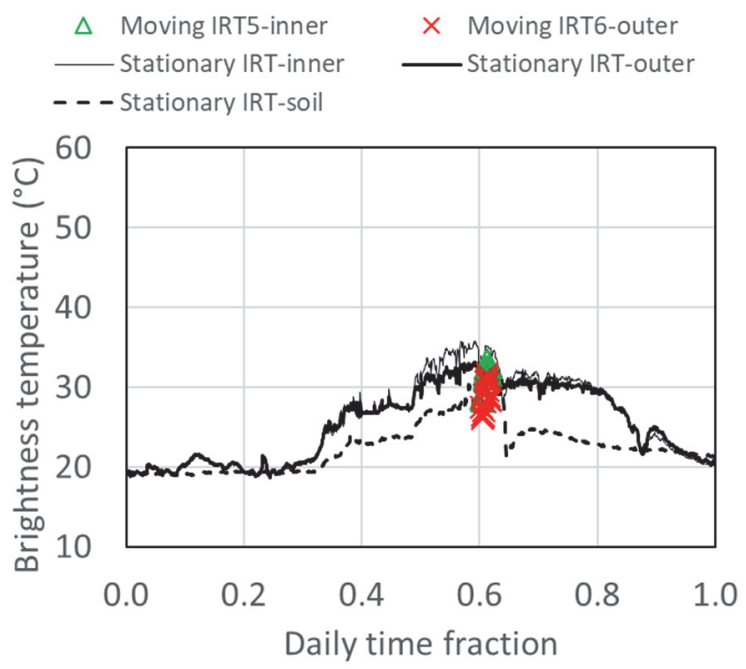

(b)

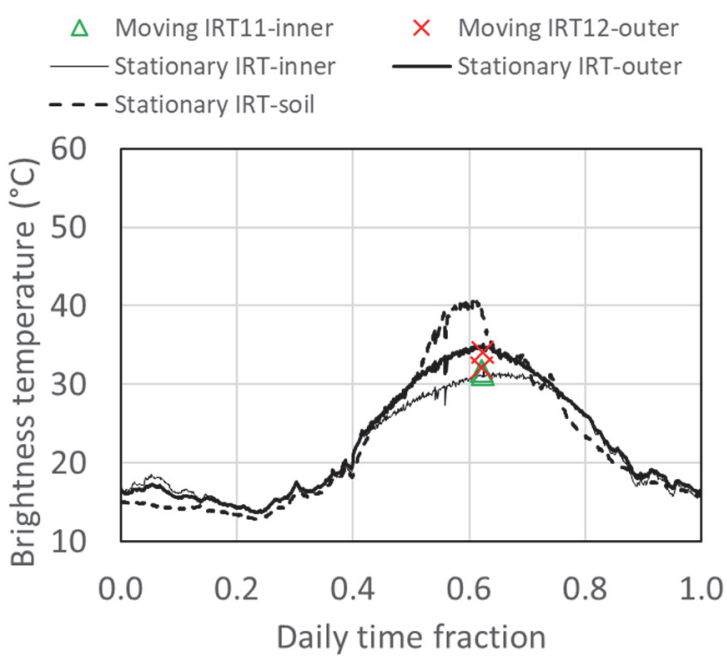

(c)
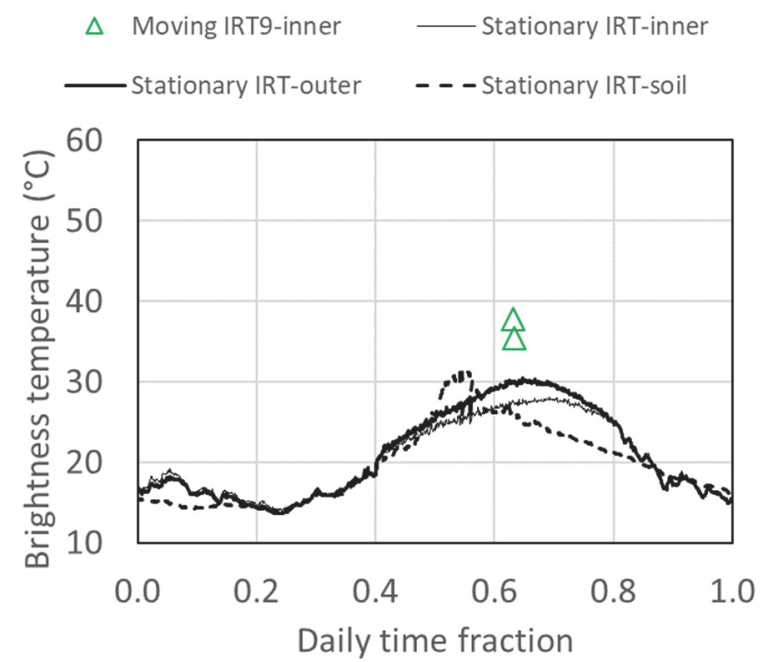

(d)

Figure 7. Diurnal directional brightness temperature $\left(T_{B}\right)$ of stationary IRTs, and $T_{B}$ of moving IRTs when passing over stationary IRT locations; (a) 2016 corn, Plot 23, 80\% irrigation rate, DOY 180; (b) 2016 corn, Plot 23, 80\% irrigation rate, DOY 206; (c) 2018 potato, Plot $34,60 \%$ irrigation rate, DOY 155; (d) 2018 potato, Plot 38, 100\% irrigation rate, DOY 155.

The addition of low-cost imaging radiometers may be the most direct and economical approach to provide real-time measurement of view factors, which are needed to extract vegetation temperature from an IRT view containing both vegetation and soil. This may also be an economical alternative to more expensive thermal imagers of comparable accuracy, and would be useful for any stationary or moving sensor platform.

\section{ACKNOWLEDGEMENTS}

This work was funded in part by the National Institute of Food and Agriculture, U.S. Department of Agriculture, under award number 2016-67021-24420; a Cooperative Research and Development Agreement (CRADA) between USDA-ARS and Dynamax, Inc., Houston, Texas (Agreement No. 58-3K95-3-16135); a CRADA between USDAARS and Valmont Industries, Inc., Valley, Nebraska (Agreement No. 58-3K95-0-1455-M); the USDA-ARS Ogallala Aquifer Program, a consortium between the USDA-ARS,
Kansas State University, Texas A\&M AgriLife Research, Texas A\&M AgriLife Extension, Texas Tech University, and West Texas A\&M University; and USDA-ARS National Program 211, Water Availability and Watershed Management. We thank Ms. Melanie Baxter, Engineering Technician Aide; Ms. Jenny Shaw, Ms. Haley Traves, and Mr. Dustin Oder, Biological Science Technician Aides; Mr. Luke Britten, Mr. Don McRoberts, and Mr. Grant Johnson, Biological Science Technicians; and Mr. Brice Ruthhardt, Support Scientist, for their work in instrument deployment, maintenance, and field operations. Dr. Charles Rush and $\mathrm{Mr}$. James Gray, Texas A\&M AgriLife Research, assisted with the experimental design and operation of the potato crop.

\section{REFERENCES}

Bordovsky, J. P. (2019). Low Energy Precision Application (LEPA) irrigation method, a forty-year review. Trans. ASABE, 62(6), 1343-1353. https://doi.org/10.13031/trans.13117 
Campbell, G. S., \& Norman, J. M. (1998). An introduction to environmental biophysics (2nd. ed.). New York, NY: SpringerVerlag. https://doi.org/10.1007/978-1-4612-1626-1

Clawson, K. L., \& Blad, B. L. (1982). Infrared thermometry for scheduling irrigation of corn. Agron. J., 74(2), 311-316. https://doi.org/10.2134/agronj1982.00021962007400020013x

Colaizzi, P. D., Evett, S. R., Brauer, D. K., Howell, T. A., Tolk, J. A., \& Copeland, K. S. (2017b). Allometric method to estimate leaf area index for row crops. Agron. J., 109(3), 883-894. https://doi.org/10.2134/agronj2016.11.0665

Colaizzi, P. D., O’Shaughnessy, S. A., \& Evett, S. R. (2018). Calibration and tests of commercial wireless infrared thermometers. Appl. Eng. Agric., 34(4), 647-658. https://doi.org/10.13031/aea.12577

Colaizzi, P. D., O'Shaughnessy, S. A., Evett, S. R., \& Mounce, R. B. (2017a). Crop evapotranspiration calculation using infrared thermometers aboard center pivots. Agric. Water Manag., 187, 173-189. https://doi.org/10.1016/j.agwat.2017.03.016

Colaizzi, P. D., O'Shaughnessy, S. A., Gowda, P. H., Evett, S. R., Howell, T. A., Kustas, W. P., \& Anderson, M. C. (2010). Radiometer footprint model to estimate sunlit and shaded components for row crops. Agron. J., 102(3), 942-955. https://doi.org/10.2134/agronj2009.0393

Evett, S. R., Schwartz, R. C., Howell, T. A., Louis Baumhardt, R., \& Copeland, K. S. (2012). Can weighing lysimeter ET represent surrounding field ET well enough to test flux station measurements of daily and sub-daily ET? Adv. Water Resour., 50, 79-90. https://doi.org/10.1016/j.advwatres.2012.07.023

FAO. (2019). AQUASTAT - Global map of irrigation areas. Rome, Italy: FAO United Nations. Retrieved from http://www.fao.org/aquastat/en/geospatial-information/globalmaps-irrigated-areas

French, A. N., Hunsaker, D. J., Clarke, T. R., Fitzgerald, G. J., Luckett, W. E., \& Pinter Jr, P. J. (2007). Energy balance estimation of evapotranspiration for wheat grown under variable management practices in central Arizona. Trans. ASABE, 50(6), 2059-2071. https://doi.org/10.13031/2013.24108

Gonzalez-Dugo, M. P., Moran, M. S., Mateos, L., \& Bryant, R. (2006). Canopy temperature variability as an indicator of crop water stress severity. Irrig. Sci., 24(4), 233240. https://doi.org/10.1007/s00271-005-0022-8

Han, M., Zhang, H., DeJonge, K. C., Comas, L. H., \& Trout, T. J. (2016). Estimating maize water stress by standard deviation of canopy temperature in thermal imagery. Agric. Water Manag., 177, 400-409. https://doi.org/10.1016/j.agwat.2016.08.031

Heilman, J. L., Heilman, W. E., \& Moore, D. G. (1981). Remote sensing of canopy temperature at incomplete cover. Agron. J., 73(3), 403-406. https://doi.org/10.2134/agronj1981.00021962007300030005x

Howell, T. A., Schneider, A. D., \& Dusek, D. A. (2002). Effects of furrow diking on corn response to limited and full sprinkler irrigation. SSSAJ, 66(1), 222-227. https://doi.org/10.2136/sssaj2002.2220

Huband, N. D. S., \& Monteith, J. L. (1986). Radiative surface temperature and energy balance of a wheat canopy. BoundaryLayer Meteorol., 36(1-2), 1-17. https://doi.org/10.1007/BF00117455

Idso, S. B., Jackson, R. D., \& Reginato, R. J. (1976). Determining emittances for use in infrared thermometry: A simple technique for expanding the utility of existing methods. J. Appl. Meteorol., 15(1), 16-20. https://doi.org/10.1175/1520-

0450(1976)015<0016:defuii >2.0.co;2
IEEE. (2005). 802.15.1-2005 - IEEE Standard for information technology - Local and metropolitan area networks. Specific requirements - Part 15.1a: Wireless Medium Access Control (MAC) and Physical Layer (PHY) specifications for Wireless Personal Area Networks (WPAN). IEEE. Retrieved from https://ieeexplore.ieee.org/document/1490827

Jackson, R. D. (1982). Canopy temperature and crop water stress. In D. Hillel (Ed.), Advances in irrigation (Vol. 1, pp. 43-85). Cambridge, MA: Elsevier. https://doi.org/10.1016/B978-0-12024301-3.50009-5

Jackson, R. D., Hatfield, J. L., Reginato, R. J., Idso, S. B., \& Pinter, P. J. (1983). Estimation of daily evapotranspiration from one time-of-day measurements. Agric. Water Manag., 7, 351-362. https://doi.org/10.1016/B978-0-444-42214-9.50031-4

Kustas, W. P., Choudhury, B. J., Inoue, Y., Pinter, P. J., Moran, M. S., Jackson, R. D., \& Reginato, R. J. (1990). Ground and aircraft infrared observations over a partially-vegetated area. Int. J. Remote Sensing, 11(3), 409-427. https://doi.org/10.1080/01431169008955030

Meron, M., Sprintsin, M., Tsipris, J., Alchanatis, V., \& Cohen, Y. (2013). Foliage temperature extraction from thermal imagery for crop water stress determination. Precision Agric., 14(5), 467477. https://doi.org/10.1007/s11119-013-9310-0

Norman, J. M., \& Becker, F. (1995). Terminology in thermal infrared remote sensing of natural surfaces. Remote Sensing Rev., 12(3-4), 159-173. https://doi.org/10.1080/02757259509532284

O’Shaughnessy, S. A., Andrade, M. A., \& Evett, S. R. (2017). Using an integrated crop water stress index for irrigation scheduling of two corn hybrids in a semi-arid region. Irrig. Sci., 35(5), 451-467. https://doi.org/10.1007/s00271-017-0552-x

O'Shaughnessy, S. A., Casanova, J. J., Evett, S. R., \& Colaizzi, P. D. (2018). Computer vision qualified infrared temperature sensor. U.S. Patent No. 9,866,768 B1.

O’Shaughnessy, S. A., Evett, S. R., \& Colaizzi, P. D. (2015). Dynamic prescription maps for site-specific variable rate irrigation of cotton. Agric. Water Manag., 159, 123-138. https://doi.org/10.1016/j.agwat.2015.06.001

O’Shaughnessy, S. A., Evett, S. R., Colaizzi, P. D., \& Howell, T. A. (2013). Wireless sensor network effectively controls center pivot irrigation of sorghum. Appl. Eng. Agric., 29(6), 853-864. https://doi.org/10.13031/aea.29.9921

O’Shaughnessy, S. A., Hebel, M. A., Evett, S. R., \& Colaizzi, P. D. (2011). Evaluation of a wireless infrared thermometer with a narrow field of view. Comput. Electron. Agric., 76(1), 59-68. https://doi.org/10.1016/j.compag.2010.12.017

Osroosh, Y., Khot, L. R., \& Peters, R. T. (2018). Economical thermal-RGB imaging system for monitoring agricultural crops. Comput. Electron. Agric., 147, 34-43. https://doi.org/10.1016/j.compag.2018.02.018

Peters, R. T., \& Evett Steven, R. (2008). Automation of a center pivot using the temperature-time-threshold method of irrigation scheduling. J. Irrig. Drain. Eng., 134(3), 286-291. https://doi.org/10.1061/(ASCE)0733-9437(2008)134:3(286)

Peters, R. T., \& Evett, S. R. (2004). Modeling diurnal canopy temperature dynamics using one-time-of-day measurements and a reference temperature curve. Agron. J., 96(6), 1553-1561. https://doi.org/10.2134/agronj2004.1553

Quebrajo, L., Perez-Ruiz, M., Perez-Urrestarazu, L., Martinez, G., \& Egea, G. (2018). Linking thermal imaging and soil remote sensing to enhance irrigation management of sugar beet. Biosyst. Eng., 165, 77-87. https://doi.org/10.1016/j.biosystemseng.2017.08.013 
Rud, R., Cohen, Y., Alchanatis, V., Levi, A., Brikman, R., Shenderey, C.,... Nogon, T. (2014). Crop water stress index derived from multi-year ground and aerial thermal images as an indicator of potato water status. Precision Agric., 15(3), 273289. https://doi.org/10.1007/s11119-014-9351-z

Sadler, E. J., Camp, C. R., Evans, D. E., \& Millen, J. A. (2002). Corn canopy temperatures measured with a moving infrared thermometer array. Trans. ASAE, 45(3), 581-591. https://doi.org/10.13031/2013.8855

Santesteban, L. G., Di Gennaro, S. F., Herrero-Langreo, A., Miranda, C., Royo, J. B., \& Matese, A. (2017). High-resolution UAV-based thermal imaging to estimate the instantaneous and seasonal variability of plant water status within a vineyard. Agric. Water Manag., 183, 49-59. https://doi.org/10.1016/j.agwat.2016.08.026

Schneider, A. D., \& Howell, T. A. (2000). Surface runoff due to LEPA and spray irrigation of a slowly permeable soil. Trans. ASAE, 43(5), 1089-1095. https://doi.org/10.13031/2013.3001

Sepulveda-Reyes, D., Ingram, B., Bardeen, M., Zuniga, M., OrtegaFarias, S., \& Poblete-Echeverria, C. (2016). Selecting canopy zones and thresholding approaches to assess grapevine water status by using aerial and ground-based thermal imaging. Remote Sensing, 8(10), 822. https://doi.org/10.3390/rs8100822
Tolk, J. A., \& Evett, S. R. (2012). Lower limits of crop water use in three soil textural classes. SSSAJ, 76(2), 607-616. https://doi.org/10.2136/sssaj2011.0248

Unger, P. W., \& Pringle, F. B. (1981). Pullman soils: Distribution, importance, and management. Bull. No. 1372. College Station: Texas A\&M University, Texas Agricultural Experiment Station.

USDA-NASS. (2014). Farm and Ranch Irrigation Survey (2013), Vol. 3, Special Studies, Part 1. Washington, DC: USDA-NASS. Retrieved from

https://www.nass.usda.gov/Publications/AgCensus/2012/Online Resources/Farm_and Ranch_Irrigation_Survey/

USDA-NRCS. (2019). Soil survey TX375: Potter County, Texas. Washington, DC: USDA-NRCS. Retrieved from http://websoilsurvey.nrcs.usda.gov

Wanjura, D. F., \& Upchurch, D. R. (1991). Infrared thermometer calibration and viewing method effects on canopy temperature measurement. Agric. Forest Meteorol., 55(3), 309-321. https://doi.org/10.1016/0168-1923(91)90068-2 